\title{
Wissensordnungen, Wissbares und das Unbehagen der literarischen Repräsentation: Gibt es einen Mythosdiskurs des Mittelalters?
}

Erschienen in: Zwischen Präsenz und Repräsentation : Formen und Funktionen des Mythos in theoretischen und literarischen Diskursen / Gebert, Bent; Mayer, Uwe (Hrsg.). - Berlin : De Gruyter, 2014. - (linguae \& litterae ; 26). - S. 88-121. - ISBN 978-3-11-030752-8 https://dx.doi.org/10.1515/9783110332827.88

\section{Kontinuität - Okkupation - Alterität: \\ Paradigmen mediävistischer Mythosforschung}

Seit den Anfängen ihrer Fachgeschichte bringt die Mediävistik den Mythosbegriff mit der Entstehung volkssprachlicher Literaturen im Mittelalter in Verbindung. ${ }^{1}$ Und noch in der aktuellen Diskussion scheint kaum eine andere Epoche Vokabeln wie Mythos und mythisch so anzuziehen wie das Mittelalter. ${ }^{2}$ Trot $z$ dieser Ausgangslage erweist sich das Verhältnis der mediävistischen Literaturwissenschaften zum Mythosbegriff als ausgesprochen ambivalent: Was in mittelalterlicher Literatur und Kultur als Mythos oder Mythisches verstanden werden kann, zeigt sich je anders in den Perspektiven kontroverser Paradigmen. ${ }^{3}$ Dies hat allgemein akzeptierte Begriffsklärungen ebenso erschwert wie Versuche, sich über kontrollierte

1 Vgl. etwa Jacob Grimm, "Gedanken über Mythos, Epos und Geschichte«, in: Werke. Abteilung 1, Bd. 4: Kleinere Scbriften. Rezensionen und vermischte Aufsätze 1. Teil. Nach der Ausgabe von Karl Müllenhoff und Eduard Ippel. Otfried Ehrismann (Hrsg.), Hildesheim 1991, S. 74-85; der erstmals 1813 in Friedrich Schlegels Deutschem Museum veröffentlichte Aufsatz führt Heldenepik auf die Verbindung von Mythos und Geschichte zurück. Ausführlich dokumentiert auch Jacob Grimms Deutsche Mythologie (1835) die Geltung des Mythosbegriffs für die Proto-Mediävistik. Vgl. hierzu Beate Kellner, Grimms Mytben. Studien zum Mythosbegriff und seiner Anvendung in Jacob Grimms »Deutscher Mythologie«, Frankfurt a. M. 1994.

2 Eine Bestandsaufnahme zur Prominenz des Mythosbegriffs in der Mediävistik ist angesichts der Zahl ihrer Beiträge kaum zu leisten: Allein im Zeitraum 1999-2009 erschienen weit über 1000 mediävistische Studien, die den Mythosbegriff nicht nur polemisch anzitieren. Anstelle einer tour de force durch diese Forschungslandschaft beschränke ich mich daher im Folgenden auf wenige Hinweise zu einschlägigen Arbeiten.

3 Einschlägige Perspektiven dieser Diskussion haben zuletzt Udo Friedrich und Bruno Quast vorgestellt: vgl. Udo Friedrich/Bruno Quast, »Mediävistische Mythosforschung", in: Dies. (Hrsg.), Präsenz des Mythos. Konfigurationen einer Denkform in Mittelalter und Frïher Neuzeit, Berlin, New York 2004, S. IX-XXXVII. 
Verwendungsweisen der unterschiedlichen Mythosbegriffe der Mediävistik zu verständigen. ${ }^{4}$

Dabei lassen sich trotz der Vielfalt der Beschreibungsansätze zwei gegenläufige Standardannahmen identifizieren, die den Blick der mediävistischen Mythosforschung prägen. ${ }^{5}$ Eine dieser Standardannahmen könnte man als Kontinuitätsthese zusammenfassen: Frühchristliche Apologeten wie Origenes und Tertullian übernehmen Muster der antiken Mythoskritik, um konkurrierende theologische Systeme als leere Erdichtungen zu brandmarken, womit sie wichtige Weichen für die mittelalterliche Theologie stellen. ${ }^{6}$ Mittelalterliche Gelehrte von der Patristik über die sogenannte SSchule von Chartres im 12. Jahrhundert bis zu den Ovid-Mythographen des Spätmittelalters greifen auf antike Grammatiker wie Macrobius und Servius oder auf Mythographen wie Fulgentius zurück, um im Zuge allegoretischer Mythenauslegung universalhistorisches, naturphilosophisches und religiöses Wissen zu erzeugen. ${ }^{7}$ Solche Anschlüsse an antike Traditionen bleiben jedoch keineswegs auf gelehrte Diskurse beschränkt. Auch laikale Adelskulturen des Mittelalters suchen genealogische Kontinuität zu Spitzenahnen und Heroen der antiken Mythologie, um Herrschaftsansprüche und symbolische Selbstdeutungen $z u$ stabilisieren. ${ }^{8}$ Aufgrund solcher Beispiele lässt sich also ein Fortleben antiker Mythosdiskurse im Mittelalter konstatieren, wenngleich

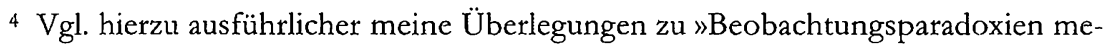
diävistischer Mythosforschung«, in: Poetica 43/2011, S. 19-61.

5 Der folgende Befund berührt sich mit der Beobachtung von Manfred Kern, Edle Tropfen vom Helikon. Zur Anspielungsrezeption der antiken Mythologie in der deutschen böffschen Lyrik und Epik von 1180-1300, Amsterdam 1998, S. 6-14, der Paradigmen der 'Kontinuität und `Diskontinuitätı unterscheidet.

6 Vgl. zusammenfassend Axel Horstmann, »Der Mythosbegriff vom frühen Christentum bis zur Gegenwart«, in: Archiv für Begriffsgeschichte 23/1979, S. 7-54 und S. 197-245.

7 Vgl. u.a. Karl Stackmann, „Ovid im deutschen Mittelalter«, in: arcadia 1/1966, S. 231-254; Brian Stock, Myth and Science in the Twelfth Century. A Study of Bernard Silvester, Princeton 1972; Paule Demats, Fabula. Trois études de mythographie antique et médiévale, Genf 1973; Peter Dronke, Fabula. Explorations into the Uses of Myth in Medieval Platonism, Leiden, Köln 1974; Renate Blumenfeld-Kosinski, Reading Myth. Classical Mythology and its Interpretations in Medieval French Literature, Stanford 1997; Jane Chance, Medieval Mythography. Bd. 1: From Roman North Africa to the School of Chartres, A.D. 433-1177. Bd 2: From the School of Chartres to the Court of Avignon, Gainesville 1994-2000; Emmanuèle Baumgartner/Laurence Harf-Lancner (Hrsg.), Lectures et usages d'Ovide (XIIIè-XVè siècle), Paris 2002.

8 Dies hat eindrucksvoll Beate Kellner nachgezeichnet: vgl. Beate Kellner, Ursprung und Kontinuität. Studien zum genealogischen Wissen im Mittelalter, München 2004. 
sich dies für viele Studien bei genauerer Betrachtung als ein produktives Dahinsterben entpuppt.?

Dieser Kontinuitätsthese wurden vielfache Differenzen und Brüche zwischen antiken Mythosdiskursen und mittelalterlichen Wissenschaften und Künsten entgegengehalten. Antike Mythosdiskurse - so argumentierten etwa Erwin Panofsky, Hans Blumenberg und Hans Robert Jauß - würden von Theologen, Philosophen und Künstlern des Mittelalters im christlichen Bezeichnungssystem der Allegorese gebannt, deren Fesseln erst Remythisierungsprojekte wie die Liebesmythologie Dantes oder die italienische Renaissancemalerei des 15. Jahrhunderts aufsprengten. ${ }^{10}$ Folgt man der Leitmetapher der Gefangenschaft antiker Mythen in mittelalterlichen Zeichenordnungen (Blumenberg/Jauß), könnte man dieses Argumentationsmuster als Okkupationsthese des Mythos fassen. Auch sie prägt weiterhin den mediävistischen Begriffsgebrauch. ${ }^{11}$

9 Ich beziehe mich damit auf die Epochenmetaphorik des Verfalls, die einflussreich Jean Seznec für das Kontinuitätsmodell geprägt hat: Die Renaissance-Humanisten hätten nicht immer »aus den lebendigen und reinen Quellen des Altertums« geschöpft, sondern auf mythologisches Wissen des Mittelalters zurückgegriffen "ein Konglomerat aus heterogenen Bestandteilen, in welchem unter von der Zeit zerfressenen Kupfermünzen einige Goldstücke blinken«; Jean Seznec, Das Fortleben der antiken Götter. Die mythologische Tradition im Humanismus und in der Kunst der Renaissance, München 1990, S. 246. Zur Metapher des >Fortlebensı vgl. auch Friedrich von Bezold, Das Fortleben der antiken Götter im mittelalterlicben Humanismus, Aalen 1962.

10 So vor allem Hans Blumenberg, "Wirklichkeitsbegriff und Wirkungspotential des Mythos«, in: Manfred Fuhrmann (Hrsg.), Terror und Spiel. Probleme der Mythenrezeption, München 1971, S. 11-66, insbes. S. 66. Dass die Allegorese jedoch selbst schon zu den antiken Verfahren der Mythenauslegung gehört, wird von dieser Argumentation als Kontinuitätsmerkmal zumeist abgeschwächt. - Zu Dante und antiallegoretischen Tendenzen seit dem 12. Jahrhundert vgl. Hans Robert Jauß, »Allegorese, Remythisierung und neuer Mythos. Bemerkungen zur christlichen Gefangenschaft der Mythologie im Mittelalter«, in: ebd., S. 187-209. Destruktionstendenzen der smythenfeindlichen Allegorie bilden auch das Thema der Diskussion zu »Mittelalter und Renaissance«, ebd., S. 617-637. - Aus kunstgeschichtlicher Sicht einflussreich hat Erwin Panofsky die mittelalterliche Allegorese als Entfremdung des antiken Mythos beschrieben: Zur "Versöhnung" der allegoretischen >Disjunktion von Form und Inhalt bei Andrea del Castagno und Andrea Mantegna um 1460 vgl. Erwin Panofsky, Die Renaissancen der europäischen Kunst, Frankfurt a. M. 1990, insbes. S. 178-183. Die fortgesetzte Geltung dieses Argumentationsmusters der >Okkupation` und `Befreiung` belegen u. a. Bruno Quast/Monika Schausten, »Amors Pfeil. Liebe zwischen Medialisierung und Mythisierung in Heinrichs von Veldeke Eneasromanu, in: Mireille Schnyder (Hrsg.), Schrift und Liebe in der Kultur des Mittelalters, Berlin, New York 2008, S. 63-82, insbes. S. 73 und S. 79 f.

11 So etwa im Hinblick auf den Tristan Gottfrieds von Straßburg Volker Mertens, »Bildersaal - Minnegrotte - Liebestrank. Zu Symbol, Allegorie und Mythos im 
Beide Standardannahmen - die Okkupationsthese wie die Kontinuitätsthese - legen indes nahe, im Mittelalter existiere kein distinkter Raum des Sprechens, Denkens und Wahrnehmens, der mit dem Ausdruck $>$ Mythos verknüpft (oder aus Beobachterperspektive verknüpfbar) wäre. Ohne Zweifel lassen sich differenzierte Auseinandersetzungen mit dem Konzept der fabula und Praktiken der Allegorese greifen - aber gibt es im spezifischen Sinne einen Mythosdiskurs des Mittelalters? Verstreuen sich die Gegenstände antiker oder neuzeitlicher Mythosdiskurse in den Wissensordnungen des Mittelalters nicht vielmehr auf die Felder der Naturphilosophie, Grammatik oder autorgebundene Rezeptionsstränge wie die Vergil- und OvidKommentierung? Verschwindet nicht selbst die Bezeichnung >Mythos` aus den Texten des Mittelalters? Beide Standardannahmen geraten durch solche Fragen in Darstellungsschwierigkeiten: Denn entweder treten vornehmlich Mythoskonzepte in den Blick, die nicht spezifisch mittelalterlich sind (Kontinuitätsthese), oder man muss ein Mittelalter ohne Mythos konstatieren (Okkupationsthese).

Auf diese Schwierigkeiten hat die jüngere Mediävistik mit theoretischer Distanzierung reagiert. Entweder wird der Mythosbegriff als unscharfer Begriff abgelehnt oder es werden neuzeitliche Mythoskonzepte in die mittelalterliche Literatur zurückgespiegelt. So plädieren etwa Udo Friedrich und Bruno Quast in ihrem 2004 vorgelegten Resümee zur mediävistischen Mythosforschung dafür, Mythos als »das Andere der Vernunft« zu verstehen das Mittelalter wird mit dieser Formulierung als Ausgrabungsfeld alteritärer Rationalitätsformen umrissen, die im Geist von Wilhelm Nestles Unterscheidung von irrationalem Mythos und rationalem Logos kartographiert werden. ${ }^{12}$ Da distinkte Mythoskonzepte mittelalterlichen Textkulturen fremd

Tristanroman«, in: Beiträge zur Geschichte der deutschen Sprache und Literatur 117/1995, S. 40-64, insbes. S. 48f.; kritisch diskutieren die `Okkupationsthese zur smythenfeindlichen mittelalterlichen Allegorese auch Alfred Ebenbauer und Ulrich Wyss: "Der mythologische Entwurf der höfischen Gesellschaft im Artusroman«, in: Gert Kaiser/Jan-Dirk Müller (Hrsg.), Höfische Literatur; Hofgesellscbaft, böfische Lebensformen um 1200, Düsseldorf 1986, S. 513-540.

12 Friedrich/Quast, »Mediävistische Mythosforschung", S. X: »Denn der Mythos lässt sich als das Andere der Vernunft verstehen, das sich einer vollständigen rationalen Auflösung entzieht. Mythostheorien konzeptionalisieren dieses Andere der Vernunft auf je eigene Artu. Diese Generalisierung des Mythosbegriffs ist angesichts des differenzierten Überblicks über historische und moderne Mythoskonzeptionen, den Friedrich und Quast bieten, durchaus überraschend. Als Leitmodell des Bandes stellen Friedrich und Quast ausdrücklich Cassirers Modell des ımythischen Denkensı zur Debatte - die definitorische Formulierung weist jedoch in andere Theorierichtungen. Vgl. dazu Gebert, »Beobachtungsparadoxien«, S. 40-42. 
scheinen, werden somit Beschreibungsmuster der Neuzeit auf sie projiziert, die Mythos vor allem unter dem Gesichtspunkt der Alterität konzipieren. Die historischen Selbstbeschreibungen und Semantiken, mit denen mittelalterliche Autoren auf antike Mythosdiskurse reagieren, diese transformieren und neu kommentieren, kommen dagegen kaum noch zu Wort.

Im Lichte zunehmend enthistorisierter und diskursiv breit gefächerter Mythosbegriffe droht jedoch der Objektbereich mediävistischer Mythosforschung zu verschwimmen: Hagens wilde Kindheitsgeschichte im KudrunEpos gilt gleichermaßen als mythisch wie die Feen- und Gralsreiche der Artusepik, mittelalterlicher Werwolf-Glauben wird ebenso als Mythos verhandelt wie Walhalla oder die Wartburg. ${ }^{13}$ Die mediävistische Mythosforschung kennzeichnet somit eine auffällige Kontingenz, wie Hans Robert Jauß schon 1968 eingestehen musste: ${ }^{14}$ Unklar ist mehr denn je, ob wir die Vokabel Mythos überhaupt benötigen, um mittelalterliche Textkulturen zu beschreiben.

Eine mögliche Antwort auf diese Frage möchte ich im Folgenden zur Diskussion stellen, indem ich Umrisse eines mittelalterlichen Mythosdiskurses rekonstruiere, der durch das beschriebene Projektionsproblem der aktuellen mediävistischen Forschung weitgehend verdeckt ist. Ich möchte damit die erste Leitfrage des vorliegenden Bandes zu der Überlegung konkretisieren, inwiefern mittelalterliche Theorien und poetische Inszenierungen der Mythosrezeption mit der Unterscheidung von Präsenz und Repräsentation operieren. Praktiken des Bezeichnens, wie sie im Folgenden exemplarisch an Mythographien, Mythostheorien und Romanen des 12. und 13. Jahrhunderts zu untersuchen sind, verweisen auf eine historische Unterscheidung von Repräsentation und Präsenz von Mythen, die sich zeichentheoretisch als Spannung von zugeschriebener Fremdreferenz und Selbstreferenz präzisieren lässt. Einerseits sprechen mittelalterliche Autoren Mythen die Funktion zu,

13 Vgl. Jan-Dirk Müller, »Verabschiedung des Mythos. Zur Hagen-Episode der Kudrumu, in: Friedrich/Quast (Hrsg.), Präsenz des Mythos, S. 197-217; José Manuel Losada Goya, „La nature mythique du Graal dans \Le Conte du Graak de Chrétien de Troyes«, in: Cabiers de civilisation médiévale 52/2009, S.3-20; Joyce Tally Lionarons, »Walhalla«, in Ulrich Müller/Werner Wunderlich (Hrsg.), Mittelalter-Mythen. Bd. 5: Burgen, Länder, Orte, Konstanz 2008, S. 945-950; Karin Cieslik, »Die Wartburg«, in: ebd., S. 951-964; Volker Mertens, Der Gral. Mythos und Literatur, Stuttgart 2003.

14 Im Rahmen der Diskussion zu »Mittelalter und Renaissance« sieht Jauß Harald Weinrich "weithin im Recht mit dem Zweifel, ob man die [...] betrachtete literarische Tradition [der Minneallegorie, B. G.] nicht auch beschreiben könnte, ohne überhaupt das Wort >Mythosı zu verwenden«; »Mittelalter und Renaissance«, S. 618 . 
in verhüllter Form auf anderweitige Gegenstände des Wissens zu verweisen. Andererseits bringen sie Mythen aber auch in ihrer wörtlichen Bedeutung und primären Bildsprache narrativ zur Geltung. Mythen werden damit von einem Diskurs verhandelt, der unablässig zwischen Zeichenhaftigkeit und Narrativität, zwischen Sinnverweisung und Selbstdarstellung pendelt. Seine schwebende Referenz produziert in lateinischen wie in volkssprachlichen Texten Aussagetypen, die weder mit Verfahren der Allegorese gleichzusetzen sind, noch in der fabula-Diskussion des Mittelalters aufgehen.

Die Referenzverschiebungen dieses historischen Diskurses verdienen besondere literaturtheoretische und literaturgeschichtliche Aufmerksamkeit, da sie signifikante Parallelen zur Evolution von fiktionalem Erzählen im 12. Jahrhundert aufweisen. Könnte die Diskursgeschichte von Mythos im Mittelalter damit systematische Schnittstellen mit jener Geschichte des Literarischen besitzen, die sich auf das spezifische Merkmal der Fiktionalität bezieht?

\section{Mythos in Wissensordnungen und Mythos als Wissbares: Zur Systematik einer übersehenen Differenz}

Die Suche nach Schnittstellen von literarischer Fiktionalität und Mythosdiskurs kann sich an einer Differenz orientieren, die im Mittelalter gegen große diskursive Widerstände entwickelt, aber zunehmend durchgesetzt wird: Redepraktiken, die antike Mythen in mittelalterliche Wissensordnungen transponieren, also auf andere Wissensformen beziehen, werden unterscheidbar von Praktiken und Konzepten, die Mythos selbst als Wissbares auffassen. Welche Konsequenzen mit einer solchen Unterscheidung verbunden sind, möchte ich mit einem kursorischen Überblick zum mythographischen Diskursfeld des Mittelalters und exemplarischen Stichproben erläutern.

Wissensformationen des Mittelalters repräsentieren antike Mythologie zumeist in der Codierungsform des integumentum (Verhüllung). ${ }^{15}$ Der Bernar-

15 Vgl. Marie-Dominique Chenu, „Involucrum. Le mythe selon les théologiens médiévaux", in: Archives d'bistoire doctrinale et littéraire du moyen âge 22/1956, S.75-79; Jane Chance, »The Origins and Development of Medieval Mythography From Homer to Dante«, in: Dies./Raymond Wells (Hrsg.), Mapping the Cosmos, Houston 1985, S. 35-64; ausführlich auch Chance, Medieval Mythography. Zur Begriffs- und Diskursgeschichte integumentaler Hermeneutik speziell im Hochmittelalter vgl. Frank Bezner, Vela veritatis. Hermeneutik, Wissen und Sprache in der Intellectual History des 12. Jabrbunderts, Leiden u. a. 2005; Haijo Jan Westra (Hrsg.), The Commentary on Martianus Capella's De Nuptiis Philologiae et Mercurii Attributed to Bernardus Silvestris, Toronto 1986, S. 23-33 [Kommentar]. 
dus Silvestris (gest. nach 1159) zugeschriebene Aeneis-Kommentar bezeichnet mit diesem Begriff »eine Weise der Darlegung, die eine wahre Vorstellung unter einer fiktiven Erzählung verhüllt, weshalb sie auch Verhüllung genannt wird «. ${ }^{16}$ Wahres unter der Hülle des Fiktiven wie etwa der Erzählung von Orpheus und Eurydike: Geradezu prototypisch für Autoren des 12. Jahrhunderts unterscheidet (Pseudo-)Bernardus mit dieser Bestimmung die Redeform des integumentum sowohl von historischer Faktizität als auch vom offenbarten oder natürlichen Sinn, den die Allegorese voraussetzt. ${ }^{17}$ Beanspruchen allegorische Schriftauslegungen des Mittelalters, wauf heilsgeschichtlichen Fakten gegründet und daher wahr zu sein «, so gehen Verhüllungstheorien umgekehrt von der freien Setzung der Dichter aus. ${ }^{18}$

Vielfältige Beschreibungs- und Auslegungspraktiken verbinden sich mit dem Begriff des integumentum vom frühen bis zum hohen Mittelalter, doch lassen sich verbindende Grundzüge erkennen:

(1.) Dominanz von Fremdreferenz über Selbstreferenz. In der Perspektive von Auslegungsprogrammen des integumentum gelten Mythen als Zeichen erster Ordnung, die auf andere Zeichenordnungen hin überschritten werden müssen. Mythen sind Erzählungen, deren verzichtbare 'Schale` erst hermeneutisch aufzubrechen ist, bevor verlässliche Referenz hergestellt und Wissen gewonnen werden kann. ${ }^{19}$

${ }^{16}$ Julian Ward Jones/Elizabeth Frances Jones (Hrsg.), The Commentary on the First Six Books of the Aeneid of Vergil commonly attributed to Bernardus Silvestris, Lincoln u. a. 1986, S. 3,14f.: »Integumentum est genus demonstrationis sub fabulosa narratione veritatis involvens intellectum, unde etiam dicitur involucrum«. Diese Definition setzt die Begriffsbildung des Macrobius fort, der im 5. Jh. die narratio fabulosa als Redeform bestimmt hatte, welche sich mittels Erdichtungen auf Wahres beziehe (»modus per figmentum vera referendik); Ambrosius Macrobius Theodosius, Commentarii in Somnium Scipionis. 2. Aufl. James Willis (Hrsg.), Leipzig 1970, S.6 $(1,2,10)$. Sämtliche Übersetzungen stammen - soweit nicht anders angegeben vom Verfasser.

17 Anders argumentiert dagegen am Beispiel des (pseudo-)bernardinischen MartianKommentars Haijo Jan Westra, "The Allegorical Interpretation of Myth. Its origins, Justification and Effectu, in: Andries Welkenhuysen/Herman Braet/Werner Verbeke (Hrsg.), Medieval Antiquity, Leuven 1995, S.277-291, der sowohl Bibelallegorese als auch Mythenexegese einem erweiterten Allegorieverständnis zuordnet.

18 Rudolf Suntrup, »Allegorese«, in: Georg Braungart u. a. (Hrsg.), Reallexikon der dentschen Literaturnissenschaft, Bd. 1, Berlin, New York 2007, S. 36-40, hier S. 37; vgl. ausführlich Hartmut Freytag, Die Theorie der allegorischen Scbriftdeutung und die Allegorie in deutschen Texten besonders des 11. und 12. Jabrbunderts, Bern 1982, insbes. S. 15-43.

19 Bereits der spätantike Mythograph Fabius Planciades Fulgentius vergleicht in seiner Thebais-Einleitung das Werk des Statius mit einer Nuss, deren Schale aufzubre- 
Schon die für mittelalterliche Mythographen einflussreichen Mitologiae des Fulgentius versammeln zu Beginn des 6. Jahrhunderts Erzählungen von Saturn, Jupiter oder dem Urteil des Paris mit dem ausdrücklichen Anspruch, ein »unter Lügen begrabenes« Wissen freizulegen: »[D]ie wahren wirksamen Kräfte der Dinge« gelte es aufzudecken, »wodurch wir - sind die Erdichtungen der lügnerischen Griechen einmal zerstört - erkennen, welche geheime Bedeutung man in ihnen entdecken muss. ${ }^{20}$ Nicht an und für sich selbst gelten Mythen somit als Kandidaten möglichen Wissens, sondern allenfalls als problematische, indirekte Vermittlungsinstanzen von Wissen.

Mythographen vom frühen bis zum späten Mittelalter entfalten dieses Argumentationsmuster zu einer weitverbreiteten Ursprungsgeschichte von Mythen, die auf einer Verkettung von metonymischer Verwechslung und irr-

chen sei, um an den Bedeutungskern zu gelangen; vgl. Fabius Planciades Fulgentius, "Expositio sermonum antiquorum ad grammaticum calcidium / super Thebaiden«, in: Opera. Accedunt Fabii Claudii Fulgentii De aetatibus mundi et hominis. Rudolf Helm (Hrsg.), Leipzig 1898, S. 180-186, hier S. 180, 14-20: win nuce enim duo sunt, testa et nucleus, sic in carminibus poeticis duo, sensus litteralis et misticus; latet nucleus sub testa: latet sub sensu litterali mistica intelligentia; ut habeas nucleum, fragenda est testa: ut figurae pateant, quatienda est littera; testa insipida est, nucleus saporem gustandi reddit: similiter non littera, sed figura palato intelligentiae sapit« (»denn wie die Nuss aus zwei Dingen besteht, aus Schale und Kern, so bestehen auch Dichtungen aus zweien, aus dem wörtlichen und dem geheimen Sinn [misticus]; damit du den Kern erhältst, ist die Schale zu zerbrechen; damit die Ausdrucksformen offen liegen, ist der buchstäbliche Sinn aufzubrechen. Die Schale ist ungenießbar, der Kern bietet genussreichen Geschmack ebenso schmeckt dem Gaumen des Verstandes nicht der Wortlaut, sondern die Ausdrucksform (). Die Nussmetaphorik von Schale und Kern wird leitend auch für mythenhermeneutische Modelle des Hochmittelalters: Adam von St. Victor, Alanus von Lille und Matthäus von Vendôme kennzeichnen damit den höheren Wert der geheimen Bedeutung gegenüber der verzichtbaren äußeren Erscheinung der Erzählung. Zur Metaphorik von cortex, testa und nucleus vgl. Hennig Brinkmann, Mittelalterliche Hermeneutike, Tübingen 1980, S.183f.; Durant W. Robertson, "Some Medieval Literary Terminology, with Special Reference to Chretien de Troyes«, in: Studies in Philology 48/1951, S. 669-692, insbes. S. 669-671.

20 Fulgentius, »Mitologiarum libri tres«, in: Opera, S. 1-80, hier S. 11, 15-18: »certos itaque nos rerum praestolamur effectus, quo sepulto mendacis Greciae fabuloso commento quid misticum in his sapere debeat cerebrum agnoscamus."Zur Bedeutung der Mitologiae für die mythographische Tradition des Mittelalters vgl. Robert Edwards, "The Heritage of Fulgentius«, in: Aldo Bernardo/Saul Levin (Hrsg.), The Classics in the Middle Ages. Papers of the Tiventieth Annual Conference of the Center for Medieval and Early Renaissance Studies, Binghamton 1990, S. 141-151. 
tümlicher Apotheose beruhe, wie beispielsweise um 1180 Alberich von London zu Beginn seiner Mythographie De diis gentium feststellt: ${ }^{21}$

In Aegypten lebte ein überaus reicher Mann namens Syrophanes. Dieser hatte einen einzigen Sohn, den er über alle Maße liebte. Es geschah, dass der Sohn starb. Aus übermächtiger Empfindung der Liebe ließ der Vater dessen Bildnis in seinem Haus aufstellen. Während er jedoch ein Heilmittel gegen die Trauer suchte, erfand er eine noch mächtigere Quelle des Schmerzes. Schließlich wurde dieses Bildnis

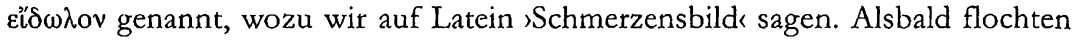
die Angehörigen seiner ganzen Familie in Verehrung des Herren Kränze für das Bildnis, opferten Blumen und entzündeten Räucherwerk. Sie erlangten Nachsicht vom Herrn, wenn sie in irgendeiner Sache Zuflucht zum Bildnis nahmen, das sie mehr aus dem Gefühl der Furcht als der Liebe verehrten. Und daher heißt es auch: >Furcht erschuf zuerst die Götter auf der Welts. Hierauf begann der fest verwurzelte menschliche Irrtum überall im heidnischen Bilderkult verbreitet zu werden. ${ }^{22}$

Alberich ruft nun dazu auf, diese medienpsychologisch verstärkte Referenzverschiebung der simulacra wieder rückgängig zu machen:

21 Vgl. als weitere Belege z. B. Fulgentius, »Mitologiarum libri«, S. 15, 20-17,8 (Kap. "Unde idolum(); Isidor von Sevilla, Etymologiarum sive Originum libri XX. Wallace Martin Lindsay (Hrsg.), Oxford 1910/1911 (8, 11, 4-14); Johannes Ridewall, Fulgentius metaforalis (erstmals 1333/1334 erwähnt), zit. in: Hans Liebeschütz, Fulgentius metaforalis. Ein Beitrag zur Geschicbte der antiken Mytbologie im Mittelalter, Leipzig, Berlin 1926, S. 65-71 (Kap. „Ydolatria«).

22 Alberich von London, »De diis gentium et illorum allegoriis«, in: Scriptores rerum mythicarum latini tres Romae nuper reperti. Ad fidem codicum Mss. Guelferbytanorum Gottingensis, Gothani et Parisiensis. Georg Heinrich Bode (Hrsg.), Bd. 1, Celle 1834, S. 152-256, hier S. 152, 4-16: „Fuit in Aegypto vir ditissimus, nomine Syrophanes. Hic habuit filium unigenitum, quem immodice diligebat. Contigit filium mori. Ejus simulacrum pater prae nimio dilectionis affectu in aedibus suis constituit; dumque tristitiae quaesivit remedium, seminarium potius doloris invenit. Denique

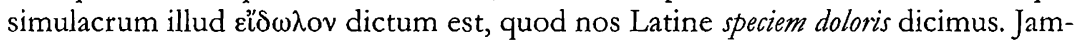
que universa domini familia in domini adulationem coronas simulacro plectebant, flores offerebant, odoramenta succendebant. Rei etiam ad simulacrum confugientes, veniam a domino adepti sunt, veneratique sunt illud magis timoris affectu quam amoris; unde et dictum est: Primus in orbe deos fecit timor. Exhinc inveteratus error humanus in idolorum cultu ubique gentium coepit diffundi [...] « [Kursivierungen im Original]. Alberichs Mythographie ist auch bekannt unter dem älteren Verfassertitel »Mythographus tertius vaticanus«; zu Alberich vgl. Henning Sjöström, "Magister Albericus Lundoniensis, mythographus tertius vaticanus. A XIIIth century student of classical mythology", in: Classica et mediaevalia 29/1968, S. 249-264. 
Nun aber wollen wir nacheinander einige dunkle Irrtümer des Altertums wieder überdenken, und wenn wir sie nicht erhellen können, wollen wir dennoch einige Nebel des Unwissens mit der Geißel des Rates der Autoritäten vertreiben. ${ }^{23}$

Alberichs Geißel treibt mythologischen Erzählungen im nachfolgenden Hauptteil der Mythographie ihre Irrtümer aus, indem diese auf andere, als eigentlich erklärte Signifikate bezogen werden. Das Urteil des Paris und der Göttinnenstreit zwischen Venus, Juno und Minerva ist für Alberich - wie schon zuvor für Fulgentius und nach ihm auch für Autoren wie Johannes Ridewall und Petrus Berchorius zu Beginn des 14. Jahrhunderts - eigentlich eine Debatte über kontemplative, aktive und lustorientierte Lebensweisen. ${ }^{24}$ Welche Komplexität solche referentiellen Rückstellungen gewinnen, belegt schon ein kurzer Ausschnitt aus Alberichs Eintrag zu Juppiter:

Sie halten Juppiter und Juno, das heißt Feuer und Luft, für Geschwister, da diese Elemente die gleiche Klarheit besitzen. Da Juno, das heißt die Luft, tatsächlich dem Feuer unterworfen ist, wurde ihnen zu Recht die Bezeichnung >Ehegatten verliehen. Denn sie sagen, ihr beider Name komme vom `Helfen، Nichts erhält nämlich alles so am Leben wie die Wärme. Auch kann kein Tier ohne Luft überleben. Außerdem wird Juppiter auf Griechisch Zzù s genannt, was auf Latein mit ,Wärmer oder `Leben zu übersetzen ist, da nämlich dies Element glüht und Heraklit zufolge alles durch das Lebensfeuer belebt ist. Daher wird Juppiter gleichsam 'hilfreicher Vater، genannt. ${ }^{25}$

23 Alberich von London, »De diis gentium «, S. 153, 13-16: »Nunc autem deinceps inexplicitos aliquot antiquitatis revolvamus errores, iisque si non lucem infundere possumus, aliquas tamen ignorantiae nebulas majorum flagello auctoritatum aliquatenus dimoveamus«. Zur Kontinuität der Vorstellung vom verdeckenden Charakter von Mythen und der Leitmetaphorik von Nebel und Auflösung vgl. z. B. um 1234 Johannes von Garland, Integumenta Ovidii. Fausto Ghisalberti (Hrsg.), Messina, Mailand 1933, S. 35 (1, 5-8).

${ }^{24}$ Alberich von London, „De diis gentium«, S. 240-242 (11, 21-23); vgl. Fulgentius, »Mitologiarum libri«, S. 36, 1-37, 20 (»Fabula de iudicio Paridis«). Zu Ridewall vgl. Liebeschütz, Fulgentius metaforalis, S. 56 (Kapitelübersicht nach der Erfurter Handschrift: »Paris iusticia«, »Minerva vita contempl.«, »Juno vita activa«, »Venus vita luxur.«); vgl. Petrus Berchorius, Reductorium morale, Liber XV: Ovidius moralizatus. Cap. i. De formis figurisque deorum. Textus e codice Brux., Bibl. Reg. 863-9. Institut voor Laat Latijn der Rijksuniversiteit Utrecht (Hrsg.), Utrecht 1966, S. 53, 17-54, 58 (»Nupcie Pelei \& Thetidis«).

25 Alberich von London, »De diis gentium«, S. 160, 23-33: JJovem et Junonem, id est ignem et aerem quoniam paria tenuitate elementa esse videntur, germanos esse dixerunt. Quia vero Juno, hoc est aer, igni subjecta est, jure superposita mariti nomen datum est. Hos autem ambos a juvando dixerunt. Nulla enim res sic fovet omnia, quemadmodum calor. Nec sine aere ullum animal vivere potest. Praeterea Graece Juppiter Zev̀s dicitur, quod Latine calor sive vita interpretatur, quod videlicet hoc elementum caleat; et quod igni vitali, ut Heraclitus vult, omnia sint animata. Juppiter ergo quasi juvans pater nuncupatur" [Kursivierungen im Original]. 
Der Ausdruck )Juppiter wird so von der Bezeichnung eines Gottes nacheinander auf vielfältige andere Wissensformen re-referentialisiert: auf physikalisches Wissen (»ignis«, »calor«), auf Sprachwissen von Etymologie und

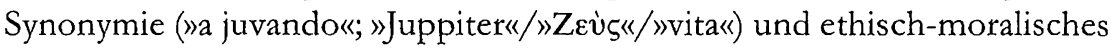
Wissen (»juvans pater«).

Alberich steht mit dieser Verfahrensweise der Referentialisierung im zeitgenössischen Feld der Mythographie nicht allein. Arnulf von Orleans erklärt um 1180 Ovids Metamorphosen zu verhüllten Repräsentationen physischer und psychischer Veränderungen - gleichsam zu Aristoteles-Studien unter verzichtbarer poetischer Verkleidung. ${ }^{26}$ Für die sogenannte Digby-Mythographie aus dem letzten Viertel des 12. Jahrhunderts bezeichnen die Taten des Hercules eigentlich den stufenweisen Aufstieg von gewaltsamer Praxis zum philosophischen Leben der Kontemplation. ${ }^{27}$

Stets werden Mythen in diesen und anderen Mythographien des Mittelalters als verkrümmte Indizes von physikalischem, moralischem, psychischem, theologischem, philosophischem, sprachlichem oder ökonomischem Wissen lesbar gemacht. Zugeschriebene Fremdreferenz dominiert in diesen Fällen über die zugeschriebene Selbstreferenz von Mythen: Als entscheidend werden ihre Anschlussmöglichkeiten auf Anderes gewertet, "per unum significatur aliud« (»durch eines wird ein anderes bezeichnet«), wie Galfried von Vinsauf in seinem Rhetoriklehrbuch programmatisch festhält. ${ }^{28}$

Im Rückgriff auf Gottlob Freges Unterscheidung zwischen Bedeutung und Sinn ließe sich diese charakteristische Reorganisation der Referenz weiter präzisieren: ${ }^{29}$ Wenn `Jupiter» nicht einen Gott, sondern den feurigen Äther

Vgl. Arnulf von Orleans, »Allegoriae super Ovidii Metamorphosin«, in: Arnolfo d'Orleans. Un cultore di Ovidio nel seculo XII. Fausto Ghisalberti (Hrsg.), Mailand 1932, S. 157-234. Speziell zu Arnulf im Kontext der Ovidrezeption vgl. Ralph Hexter, "Medieval Articulations of Ovid's Metamorphoses. From Lactantian Segmentation to Arnulfian Allegory«, in: Mediaevalia 13/1989, S.63-82; Chance, Medieval Mythography. Bd 2, S. 56-81.

27 Überliefert ist die Digby-Mythographie unter dem Werktitel Liber de natura deorum in der Handschrift Oxford, Bodleian Library, Digby 221, fol. 100r-120v. Abdruck bei Virginia Brown, "An Edition of an Anonymous Twelfth-Century Liber de natura deorumw, in: Medieval Studies 34/1972, S. 1-70; vgl. hierzu Judson Boyce Allen, "An Anonymous Twelfth-Century `De Natura Deorum«, in: Traditio 26/1970, S. 352-364.

28 Vgl. Galfried von Vinsauf, „Summa de coloribus thetoricis«, in: Les arts poétiques $d u$ XIIe et du XIIIe siècle. Recherches et documents sur la technique littéraire du moyen âge. Edmond Faral (Hrsg.), Paris 1958, S. 321-327, hier S.326. Galfried erläutert an dieser Stelle die Figur der significatio anhand mythologischer Beispiele.

29 Vgl. Gottlob Frege, „Über Sinn und Bedeutung", in: Funktion, Begriff, Bedeutung. Fiün logische Studien. Günther Patzig (Hrsg.), Göttingen 2008, S. 23-46. 
oder die lebensspendende Wärme meint, so behaupten mittelalterliche Mythographen damit gleichbleibende Bedeutung, während sie einen irreführenden Sinn (im Beispiel Alberichs: »deus«) durch Ketten von bezeichnungsfähigen Sinnmöglichkeiten (bei Alberich nacheinander: »ignis«, »calor«, »vita«, »juvans pater« u. a.m.) ersetzen. Selbstreferenz von Mythen wird dadurch auf ein Minimalmaß reduziert. Mythen erscheinen dadurch zwar als Elemente innerhalb mittelalterlicher Wissensordnungen, sind jedoch für sich selbst nichts Wissbares. Mythen signifizieren und repräsentieren, doch werden ihnen eigenständige Präsenz und Selbstreferenz weitestgehend abgesprochen. ${ }^{30}$

(2.) Umstellungen. So wenig freilich Selbstreferenz und Fremdreferenz grundsätzlich voneinander entkoppelbar sind, so wenig können primäre Erzählung und als seigentlich deklarierter Sinn von Mythen voneinander entkoppelt werden: Ihre Erzählungen werden auch von mittelalterlichen Mythographen - wie fragmentarisch und reduziert auch immer - zunächst reproduziert, bevor sie hermeneutisch destruiert werden. Zahlreiche Texte entfalten dabei paradoxe Spannungsverhältnisse, wenn sie zugunsten von Fremdreferenz auf aggressive Weise die Selbstreferenz von Mythen auszulöschen suchen. Narrative `Hüllen kär eingestuft, sondern immer wieder als verzichtbar, ja geradezu gefährlich deklariert: »Nach physikalischen Begründungen frage ich, nicht nach Geschichten«, poltert etwa der Graf von Anjou im Dragmaticon Wilhelms von Conches, als ihm von Narcissus und Echo erzählt wird - was zähle, sei allein die nackte Wahrheit (»nuda veritas «), nicht das Schicksal einer fiktiven Nymphe. ${ }^{31}$ Mythen stünden Wissen geradezu entgegen, wie Alanus von Lille mit der Figur einer klagenden Natur inszeniert, die wahres Wissen über sich dadurch als Mysterium geheimzuhalten sucht, dass sie in figurativer Rede fal-

30 Mit dieser semiotischen Engführung der Begriffspaare Repräsentation/Fremdreferenz und Präsenz/Selbstreferenz folge ich mittelalterlichem Begriffsgebrauch: »idem est repraesentare quod significare «; Thomas von Aquin, »In quattuor libros sententiarum«, in: Opera Omnia, Bd. 1, Roberto Busa (Hrsg.), Stuttgart-Bad Cannstatt 1980, S. $417(1,1,1$ e, 4). Dabei ist zu betonen, dass die Unterscheidung von Selbstreferenz und Fremdreferenz in mittelalterlicher Mythographie als Zuschreibung verwendet wird; nicht geht es (im strengen systemtheoretischen Sinne von Selbstreferenz) um reine Selbstbezüglichkeit von Mythen auf Mythen, sondern um Auslegungskommunikation, die Mythen auf vordergründig-wörtliche bzw. anderweitig gegebene Signifikate bezieht.

31 Wilhelm von Conches, Dragmaticon philosopbiae. Summa de philosopbia in vulgari. Italo Ronca/Lola Badia (Hrsg.), Turnhout 1997, S.255f.: »Physicam rei rationem, non fabulam quero«; vgl. dazu Bezner, Vela veritatis, S. 299-337. 
sche Göttergeschichten kolportiert. ${ }^{32}$ Der Signifikation läuft damit bei Wilhelm und Alanus stets Narration voraus: Bevor Mythen enthüllt werden können, werden diese erzählt. Mythographien gebärden sich so weder als Assimilation noch als Auslegung, sondern stets als fundamentale Korrekturen. Wenn in Kommentaren des 12. und 13. Jahrhunderts Jupiter für das Himmelsfeuer oder Aeneas' Reise von Troja nach Rom für die Reise der Seele durch den Kosmos stehen, so basieren solche Aussagen auf der Paradoxie, dass mythische Rede nicht meint, was sie sagt, während sie sagen muss, was sie nicht meint. ${ }^{33}$

Geistliche Allegorese, dies unterstreichen im 12. und 13. Jahrhundert unter anderem Hugo von St. Victor, Johannes von Salisbury und Thomas von Aquin, setzt dagegen stets das Fundament eines wahrheitsfähigen Literalsinns voraus, der Mythen gerade abgesprochen wird: Jakob unterscheide sich von Orpheus vor allem darin, dass er wirklich existiert habe, wie ein Martian-Kommentar Mitte des 12. Jahrhunderts lapidar bemerkt. ${ }^{34}$ Bibelallego-

32 Alanus von Lille, De planctu Naturae. Nikolaus M. Häring (Hrsg.), Spoleto 1978, S. 828 (Prosa 3, 121-124): „Sed tamen plerisque mee potestatis faciem palliare decreui figuris, defendens a uilitate secretum, ne si eis de me familiarem impartirem scientiam, que apud eos primitus ignota uigerent, postmodum iam nota uilescerent.« (»Ich habe mich jedoch entschieden, vielen gegenüber die Art meiner Macht durch Redefiguren zu verhüllen, um mein Geheimnis vor Geringschätzung zu schützen, damit nicht - sofern ich ihnen eine intime Kenntnis von mir gewähren sollte - das, was zuerst bei ihnen in Ansehen stand, weil es ihnen unbekannt war, später an Wert verliert, da es bekannt ist.«). Im Hintergrund steht das von Hilarius von Poitiers entwickelte Argument, naturphilosophische Mysterien seien durch Verhüllung vor Profanierung zu schützen.

33 Vgl. Bezner, Vela veritatis, S. 59.

34 Vgl. Westra (Hrsg.), Commentary on Martianus, S. 45 (2, 71-78): »Est autem allegoria oratio sub historica narratione verum et ab exteriori diversum involvens intellectum, ut de lucta Iacob. Integumentum vero est oratio sub fabulosa narratione verum claudens intellectum, ut de Orpheo«. ( $(D i e$ Allegorie ist eine Rede, die wahres und vielfältiges Verständnis unter einer historischen Geschichte verhüllt, wie der Kampf Jakobs. Das integumentum aber ist eine Rede, die wahres Verständnis unter einer erdichteten Erzählung verbirgt wie diejenige von Orpheus«). Zur Abgrenzung von allegoretischer Bibelhermeneutik und integumentaler Mythoshermeneutik vgl. auch Fritz Peter Knapp, »Historische Wahrheit und poetische Lüge. Die Gattungen weltlicher Epik und ihre theoretische Rechtfertigung im Hochmittelalter", in: Deutsche Vierteljabrsscbrift für Literaturnissenschaft und Geistesgeschichte 54/1980, S. 581-635; anders im Hinblick auf einen erweiterten Allegoriebegriff dagegen Brinkmann, Mittelalterliche Hermeneutik, S. 292-317 sowie Ingrid Kasten, "Heinrich von Veldeke: Eneasroman«, in: Horst Brunner (Hrsg.), Mittelhochdeutsche Romane und Heldenepen. Interpretationen, Stuttgart 1993, S. 75-96, insbes. S. 78f., die integumentale und allegorische Hermeneutik gleichsetzen. 
rese und Mythoshermeneutik teilen freilich gemeinsame Metaphern und Leitbegriffe der tropologischen Rede (z. B. Unterscheidungen von sensus spiritualis und sensus literalis; Übertragungssignale wie per tropologiam, mystice u. a.). Doch während der Literalsinn vorchristlicher Erzählungen des Alten Testaments zumeist als historisch wahre und daher zu bewahrende Basis für die aus ihm entwickelbaren Spiritualsinne betrachtet wird, sind Mythen seit der Patristik mit dem Verdacht belegt, schon in ihrer primären Bildsprache wahres Wissen zu verfehlen, zu verfälschen und zu verzerren. ${ }^{35}$

Wahrheitsfähig wird Mythenreferenz erst, wenn sie auf autorisierte Wissensformate umgestellt wird, was in mythographischen Texten eine förmliche Transferwut entfesselt. Nicht ohne Grund illustrieren daher Rhetoriken des 12. Jahrhunderts auch in umgekehrter Richtung das Konzept der metaphorischen Übertragung anhand von Mythen:

Eine ,Übertragung`[translatio] liegt vor, wenn irgendein Ausdruck von seiner eigentlichen Bedeutung nach gewisser Ähnlichkeit auf eine uneigentliche übertragen wird, wie es in diesen Beispielen offensichtlich ist. [...] Es ist jedoch festzuhalten, dass bei Adjektiven die translatio auftritt, bei Substantiven die significatio. Eine significatio liegt vor, wenn durch eines ein anderes bezeichnet wird wie durch Jupiter die obere, durch `Juno die untere Luftschicht, durch `Phoebus` die Sonne, durch `Eolus der Wind, durch $>$ Pluto der Tartarus, durch $\gg$ Neptun das Meer, durch `Ceres` die Saat, durch `Tetis das Wasser, durch `Bachus` der Wein [...]. Eine significatio liegt ebenfalls vor, wenn durch $>$ Paris der Schöne, durch $>$ Helenar die Schöne, durch `Ulixes` der Listige, durch `Achilles` der Starke [bezeichnet wird]. ${ }^{36}$

35 Vgl. z. B. Plotin, Enneaden (3, 5, 10); Origenes, Contra Celsum (4, 29); Augustinus, De civitate dei (6/Praefatio-6, 9). Für weitere Belege vgl. Henri de Lubac, Exégèse médiévale. Les quatres sens de l'écriture, Paris 1959-1964, Bd. 2/1, S.305-363 und Bd. 2/2, S. 384-396; zum Verhältnis von Bibel- und Mythenallegorese zusammenfassend Bd. 2/2, S.396: "En réalité, sous une même êtiquette, l'allégorie chrétienne et la païenne, si elles usent d'un certain nombre de procédés analogues, n'en sont deux choses foncièrement hétérogènes; ce sont deux méthodes opposées, procédant de deux doctrines et de deux esprits opposés. « Zur Unverzichtbarkeit literaler bistoria in der Bibelexegese vgl. exemplarisch Hugo von St. Victor, Didascalicon de studio legendi. Studienbuch. Übersetzt von Thilo Offergeld (Hrsg.), Freiburg u. a. 1997, S.360f. $(6,3)$.

36 Galfried von Vinsauf, "Summa«, S.325f.: "Translatio est, quando aliqua dictio transfertur a propria significatione ad impropriam quadam similitudine, ut in his patet exemplis. [...] Notandum autem, quod translatio fit in adjectivis, significatio in subjectis. Significatio autem est quando per unum significatur aliud, ut per

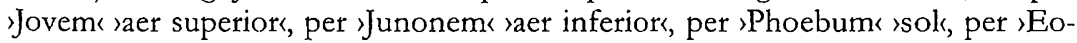

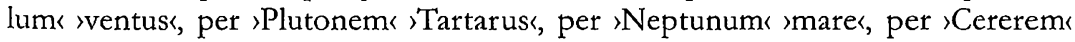

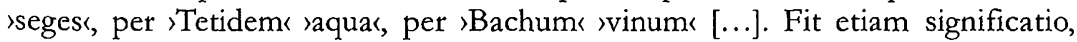

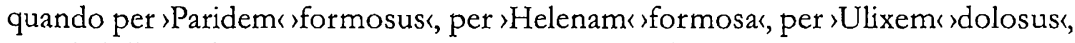
per >Achillem ^ fortis« [Kursivierungen im Original]. 
Wenn diese Ersetzungen häufig durch Semantiken von Eigenem und Anderem strukturiert werden, so gehört es gleichzeitig zu den Kuriositäten solcher Umstellungsmythologie, die Referenzverhältnisse final umzustülpen, also >von hinten nach vorn zu begründen. Phöbus und Diana seien deshalb Kinder von Jupiter und Latona, so argumentiert beispielsweise Bernardus Silvestris, weil Sonne und Mond aus den Elementen Feuer und Wasser hervorgingen; ${ }^{37}$ Vulcanus hinke, weil das Feuer niemals gerade aufsteige. ${ }^{38}$

Es wird deutlich, wie wenig dies mit bloßer >Umdeutung auf Christliches zu tun hat, wie Blumenberg einflussreich für weite Teile der mediävistischen Mythosforschung postuliert hatte. ${ }^{39}$ Vielmehr beherrschen Operationen des fremdreferentiellen Umstellens das Feld mittelalterlicher Mythographie, die unablässig zu löschen versuchen, wovon sie doch immer wieder ausgehen, und diese unablässige Aktivität von Referenzwechseln kann als ein zweiter Grundzug betrachtet werden.

(3.) Problematisierung spracblicher Repräsentation in etablierten Wissensordnungen. Wie Frank Bezner materialreich dokumentiert hat, irritiert diese Umstellungsmythologie auch die Einschätzung der Sprachdimension in etablierten Wissenschaften. Integumentale Mythoshermeneutiken eröffnen einen »komplexen, differente Gattungen überschreitenden Diskussionsraum» über das prekäre Verhältnis von uneigentlichem und eigentlichem Sprechen, in den im Laufe des 12. Jahrhunderts selbst der biblische Schöpfungsbericht hineingezogen wird. ${ }^{40}$

(4.) Deformierter Sinn - prekäre Zeichen. Texte, die Mythen als Indizes eines entstellten Sinns bearbeiten, entwickeln Redeformen, die in ihrer unablässigen Bewegung von Selbstreferenz zu Fremdreferenz die Zeichen grundsätzlich prekär werden lassen. Ihre unruhigen Bewegungen sind im hohen Mittelalter keineswegs auf die lateinischen Gelehrtenkulturen antikenbegeisterter Magister in Paris, Orleans oder Oxford beschränkt - Spuren prekärer

37 Westra (Hrsg.), Commentary on Martianus, S. 139 (6, 306f.): »Phebus et Diana filii sunt Iovis et Latone quia sol et luna effectus sunt ignis et aque«. Diese Transformation von Fremdreferenz in reigentliches, begründungsfähige Referenz registriert auch Demats, Fabula, S. 23: „L'existence d'une vérité suffit à rendre raison de n'importe quelle fable, et la fable se définit comme ce qui est dit parce que (quod dicitur quod) $\ll$.

38 So Konrad von Hirsau, »Dialogus super auctores«, in: Accessus ad auctores. Bernard D'Utrecht. Conrad D'Hirsau. Dialogus super auctores. Robert B. C. Huygens (Hrsg.), Leiden 1970, S.71-131, hier S. 85 (405f.).

39 Vgl. Hans Blumenberg, Arbeit am Mytbos, 3. Aufl., Frankfurt a. M. 1984, S. 195 und an anderen Stellen unter dem Begriff der >Umbesetzung،.

40 Vgl. Bezner, Vela veritatis, S. 559; zur Auffassung des Genesis-Berichts (insbesondere von 1 Gen 6-7) als integumentum vgl. auch Dronke, Fabula, S. 51. 
Zeichenordnungen von Mythen finden sich ebenso in volkssprachlicher Literatur.

Ich darf mich auf drei exemplarische Fälle aus der deutschsprachigen Literatur konzentrieren. Mein erstes Beispiel ist das Liet von Troye, das Herbort von Fritzlar zwischen 1190 und 1217 für den Thüringer Landgrafen verfasst. ${ }^{41}$ Das Apollon-Orakel in Delphi, so erklärt darin der Erzähler, sei in Wahrheit ein undurchschautes Gaukelspiel des Teufels gewesen, dem Heiden wie z. B. Achill vor Christi Geburt irrtümlich aufgesessen seien: ${ }^{42}$

Da3 der got were

Daz ift anders niht mere

Wen daz der tufel fathanas

Sin gelpenlte vñ lin getwas

$V_{3}$ eime bilde Iprach

Vñ fagete in fwaz in gefchach

Stille vñ vffenbare

$\mathrm{Zv}$ wane vnd $\mathrm{zv}$ ware

Beide in ernfte vñ in Ipot

Des hettē lie in vur einē got

E3 was ein heidenifche diet

Sie achtē anders geloubē niet

Diz was lange vor gotes geburt

(Dass es ein Gott gewesen sein soll, damit hat es keine andere Bewandtnis, als dass der Teufel Satan in seiner dämonischen Erscheinung aus dem Bild sprach und ihnen verkündete, was ihnen widerfahren sollte - sowohl im Geheimen als auch öffentlich, sowohl irreführend als auch wahrheitsgemäß, sowohl aufrichtig als auch höhnisch. Sie hielten ihn daher für einen Gott. Da es ein heidnisches Volk war, achteten sie keinen anderen Glauben. So war es lange vor der Geburt Gottes.)

Nach dem Vorbild frühchristlicher Apologeten diffamiert Herborts Erzähler die vermeintlichen Götter der Griechen als dämonisch erfüllte Trugbilder, die es eigentlich auf einen christlichen Referenzrahmen von Teufelsspuk und Gottesgeburt zurückzurechnen gelte. Dies hält Herborts Erzähler jedoch keineswegs davon ab, an anderen Stellen des Romans heidnische Götterkulte kommentarlos passieren zu lassen oder sogar mit Anerkennung zu erwähnen. ${ }^{43}$ Vorchristlicher Polytheismus scheint somit nicht glatt auf chris-

${ }^{41} \mathrm{Zu}$ Herborts Liet von Troye vgl. ausführlich auch Björn Reichs Beitrag in diesem Band.

${ }^{42}$ Herbort's von Fritslâr liet von Troye. Georg Carl Frommann (Hrsg.), Quedlinburg, Leipzig 1837, V. 3497-3510. Übersetzung B. G.

43 Vgl. z. B. Herbort von Fritzlar, Liet von Troye, V. 6070-6073 und V. 6121-6128. 
tozentrische Fremdreferenz umgelegt, sondern gegen eine Selbstreferenz anzuarbeiten, die narrativ mitgeführt wird. ${ }^{44}$

In ähnlicher Weise oszillieren auch Götterfiguren im Eneasroman (1170 ca. 1186) Heinrichs von Veldeke zwischen Selbstreferenz und Fremdreferenz. ${ }^{45}$ Wie seine französische Vorlage greift auch Heinrichs deutschsprachige Bearbeitung von Vergils Aeneis zu Verfahren und Vokabular der Mythenanalyse, um den Prozess der Liebesentstehung zwischen der latinischen Königstochter Lavinia und dem Exilanten Eneas darzustellen. So enthüllt die Königin ihrer Tochter in einem Aufklärungsgespräch über Wesen und Entstehung der Liebe, dass der Venussohn Amor mit seiner Büchse und seinen Pfeilen eigentlich die Minne, ihre Sehnsüchte, Qualen und Linderungsmittel bezeichne: ${ }^{46}$

dû hâst dicke wol gesehen,

wie der hêre Amôr stêt

in dem templô, dâ man in gêt

engegen der ture inne,

daz bezeichent die Minne,

diu gewaldech is ubr alliu lant.

ein buhsen hât her an der hant,

in der ander zwêne gêre:

dâ mite schûzet er vil sêre,

als ich dir sagen wolde.

$[\ldots]$

wil dû nû wizzen rehte,

${ }^{44} \mathrm{Zu}$ Herborts Montageverfahren mit mehrfacher Referenz vgl. auch Ricarda Bauschke, "Strategien des Erzählens bei Herbort von Fritzlar. Verfahren interdiskursiver Sinnkonstitution im LLiet von Troye«, in: Wolfram-Studien 18/2004, S. 347-365.

45 Diese Spannung ist verschiedentlich beobachtet worden: vgl. Marie-Luise Dittrich, "gote und got in Heinrichs von Veldeke /Eneide«, in: Zeitschrift für deutsches Altertum 90/1960/1961, S. 85-122, 198-240, 274-302; Rüdiger Schnell, Causa amoris. Liebeskonzeption und Liebesdarstellung in der mittelalterlichen Literatur, Bern u. a. 1985, S. 187-224; Hans Fromm, »Die Unterwelt des Eneas«, in: Ludger Grenzmann (Hrsg.), Pbilologie als Kulturvissenschaft. Festschrift für Karl Stackmann, Göttingen 1987, S. 71-89; Carsten Kottmann, »Gott und die Götter. Antike Tradition und mittelalterliche Gegenwart im \Eneasroman Heinrichs von Veldeke«, in: Studia Neopbilologica 73/2001, S.71-85. Auch Quast/Schausten, »Amors Pfeil« beobachten ein »Nebeneinander von mythischer Rede und Allegorese» (S. 76) in Heinrichs Zeichnung der Amor-Figur.

46 Heinrich von Veldeke, Eneasroman. Mittelhochdeutsch/Neuhochdeutsch. Nach dem Text von Ludwig Ettmüller. Ins Neuhochdeutsche übersetzt, mit einem Stellenkommentar und einem Nachwort von Dieter Kartschoke (Hrsg.), Stuttgart 1989, V. 9910-9919 und V. 9939-9946. 
waz diu buhse bedûte, dazn wizzent niht alle lûte, merke in allenthalben: si bezeichent die salben, die diu Minne ie hât gereit. diu senftet al die arbeit und machet ez allez gût, swen diu Minne wunt tût[.]

(Du hast oft schon gesehen, wie Herr Amor [gemalt] ist im Tempel, der Tür gegenüber, durch die man eintritt. Damit ist die Minne gemeint, die über die ganze Welt herrscht. Er trägt eine Büchse in der Hand und in der andern zwei Pfeile. Mit ihnen schießt er sehr kräftig, wie ich dir sagen wollte. [...] Wenn du noch genauer erfahren willst, was die Büchse bedeutet - nicht alle wissen darüber Bescheid -, so höre gut zu: Sie bedeutet die Salbe, die die Minne immer bereithält. Sie lindert alle Qual und macht alles wieder gut dadurch, daß sie heilt, wen immer die Minne verwundet.) $)^{47}$

Geradezu mustergültig vollzieht die Königin das mythographische Umstellungsprogramm: Die Selbstreferenz der Figur Amors und die Betrachtung seines Bildes mit Büchse und Pfeilen werden zunächst rekapituliert, bevor diese Accessoires ausdrücklich neu referentialisiert werden ("wil dû nû wizzen rehte, / was diu buhse bedûte«, »sie bezeichent die salben«). Wie Hilarius von Poitiers oder Alanus von Lille betrachtet auch Heinrichs Königin die Umstellung des mythologischen Bildes als korrektive Enthüllung eines höheren Geheimwissens (»dazn wizzent niht alle lûte«).

Aller integumentalen Minnelektion zum Trotz lösen sich mythologische Götterfiguren jedoch im Eneasroman keineswegs fremdreferentiell auf. Anders als in seiner französischen Vorlage bleiben Venus und Amor bei Heinrich von Veldeke an der Liebesentstehung auffällig beteiligt. Als Lavinia erstmals Eneas vom Fenster aus erblickt, schießt Venus mit einem Pfeil auf sie, woraufhin der Getroffenen zum Auftakt ihres Liebesleidens der Schweiß ausbricht: ${ }^{48}$

Dô der hêre dare quam

und sîn diu maget lussam

dâ nidene wart gewar

und si ir ougen kêrde dar,

dâ si was ûf deme hûs:

dô schôz si frouwe Vênûs

mit einer scharphen strâle. 
daz wart ir al ze quâle

sint uber ein lange stunden[.]

(Als nämlich der Herr hinkam und das liebliche Mädchen ihn dort unten erblickte und ihren Blick auf ihn richtete von ihrem Platz im Haus aus, da schoß Frau Venus mit einem scharfen Pfeil auf sie. Das brachte ihr seither nur Schmerzen für eine lange Zeit.) ${ }^{49}$

Während der fremdreferentielle Kommentar an dieser Stelle schweigt, bekräftigt Lavinia die Darstellung des Erzählers: „Amôr hât mich geschozzen / mit dem goldînen gêre ( (Amor hat auf mich geschossen mit dem goldenen Pfeil«). ${ }^{50}$ Nicht Minne entzündet die Passion, sondern Venus löst diese aus. ${ }^{51}$ Heinrichs Liebesgötter werden somit weder als Dämonen dekonstruiert, noch als die übermächtigen Handlungsdeterminanten Vergils beibehalten vielmehr beginnen Götterfiguren in den Figurenreden zwischen Selbstreferenz und Fremdreferenz zu oszillieren, und dies Schwanken lässt ihren Zeichenstatus unscharf werden.

Als drittes Beispiel für solche prekären Akte der mythographischen Referenzumstellung möchte ich den zwischen 1280 und 1287 enstandenen Trojanerkrieg Konrads von Würzburg heranziehen, weil Konrads Trojaroman diese Paradoxie irreführend realer Götterfiguren in aller Offenheit auf die Spitze treibt. Die vermeintlichen Götter der Vorzeit, so unterbricht der Erzähler gleich zu Beginn mit einem euhemeristisch-kritischen Einwurf die Hochzeitsepisode um Peleus und Thetis, seien in Wahrheit Menschen gewesen. Herausragende Menschen freilich, denen besondere magische Kompetenz oder Erfindungsleistungen zur Apotheose verholfen hätten: ${ }^{52}$

nû möhte iuch nemen wunder,

waz göte waeren bî der zît?

si wâren liute, als ir nû sît,

wan daz ir krefteclich gewalt

was michel unde manicvalt

von kriutern und von steinen.

49 Übersetzung Kartschoke, Eneasroman, S. 561.

50 Heinrich von Veldeke, Eneasroman, V. 10110f.; Übersetzung Kartschoke, Eneasroman, S. 565.

51 Vgl. Quast/Schausten, »Amors Pfeil«, S. 75: »Mythische Rede - hat auf mich geschossen - steht neben bereits abstrakter allegorischer Rede - die Liebe zu ihm hat mich verwundet; bei Heinrich von Veldeke sind beide Redeweisen, die mythische und die allegorische, zumindest der Tendenz nach weniger aufeinander bezogen, als dies im $R d E$ [= Roman d'Eneas] der Fall ist."

52 Konrad von Würzburg, Der Trojanische Krieg. Nach den Vorarbeiten K. Frommanns und F. Roths. Adelbert von Keller (Hrsg.), Stuttgart 1858, V. 858-885. Übersetzung B. G. 
ir nützen und ir reinen art si wol erkanden und tâten in den landen von ir tugende krefte und mit ir meisterschefte sô manic wunder wilde, daz man dâ von ir bilde müeste an beten iemer sît. ouch lepten gnuoge bî der zît, die zouberaere wâren und wunder in den jâren mit gougelwîse worhten. die wurden ouch mit vorhten für göte dâ geschrîet an. und ob ein sinnerîche man schoen unde niuwe liste vant, der wart ouch bî der zît erkant für einen got der selben kunst, und truogen im die liute gunst dur daz meisterlîche dinc, daz alsô niuwer fünde ursprinc von êrst ûz sînem herzen flôz.

(Nun könntet ihr fragen, was in jener Zeit Götter waren. Sie waren Menschen wie ihr heutzutage, nur dass sie große und vielfältige Macht von Kräutern und Steinen besaßen. Sie kannten ihren jeweiligen Nutzen und ihre Natur genau und wirkten an manchen Orten durch ihre mächtigen Fähigkeiten so viele fremdartige Wunder, dass man daher ihr Bildnis für alle Zeit anbetete. Auch lebten in diesen Zeiten viele Magier, die wundersames Zauberwerk trieben. Diese wurden ebenfalls aus Ehrfurcht als Götter angerufen. Und wenn ein kluger Mann eindrucksvolle, unbekannte Künste erfand, wurde er damals ebenfalls für einen Gott dieser Kunst gehalten, und die Menschen ehrten ihn für das Meisterwerk, dass auf diese Weise die Quelle neuer Entdeckungen seinem Herzen entsprang.)

Konsequent wäre es nach diesem Exkurs, Götterfiguren als Mischung von überhöhten Experten und verkappten Scharlatanen gleich zu Beginn des Trojanerkriegs zu verabschieden. Doch Konrad stärkt umgekehrt im weiteren Erzählverlauf Götterfiguren selbstreferentiell, bisweilen sogar gegen seine französische Vorlage. So motiviert etwa der Götterbote Mercur den Trojanerprinzen Paris direkt per Eilschreiben der Venus zur Raubfahrt nach Griechenland - der Roman de Troie Benoîts de Sainte-Maure hatte dagegen die Motivation in eine Traumvision verlegt und dadurch den irrealen Status der Götter markiert. ${ }^{53}$ Anders verfährt Konrad auch an vielen weiteren Stellen

53 Vgl. Konrad von Würzburg, Der Trojanische Krieg, V. 18874-18935; vgl. dagegen Benoît de Sainte-Maure, Le roman de Troie. Léopold Constans (Hrsg.), Paris 1904-1912, V. 3860-3928. 
seines Trojaromans: Im Wald von Aulis überfällt der übermächtige Meeresgott Neptun die Griechen mit einem Unwetter; 54 Achills Überlegenheit in den Kämpfen vor Troja führt der Erzähler auf das Bad im Styx zurück, ohne jedoch in diesen und anderen Fällen erneut an die fremdreferentielle Kritik des Erzählauftakts zu erinnern. ${ }^{55}$ Auch bei Konrad beginnen Göttermythen dadurch in prekärer Referentialität zu schweben.

Eine einflussreiche Forschungstradition der Mediävistik hatte - inspiriert vom Argumentationsmuster der Okkupation - in solchen Unschärfen allenfalls Schwundstufen oder Restbestände des imaginativen Eigenpotentials antiker Mythen im Mittelalter gesehen. ${ }^{56}$ Die hier aus unterschiedlichen Textsorten, sprachlichen Situierungen und historischen Kontexten versammelten Beispiele, die sich leicht vermehren ließen, nähren hingegen den Eindruck, dass diese referentielle Spannung als bloßer `Rest unterschätzt ist. Stattdessen könnte es sich empfehlen, sie als ein weiter verbreitetes Merkmal einer eigenen diskursiven Formation zu untersuchen.

Natürlich ist nicht zu bestreiten, dass literarische Inszenierungen wie der Eneasroman durch performative Darstellungsmittel und perspektivierende Erzählverfahren in anderer Weise mythologische Selbstreferenz zur Geltung bringen als stärker analytisch ausgerichtete Texte wie Alberichs Mythographie. Unterschiedliche Ausprägungen und Akzentuierungen von Selbstrefe-

54 Vgl. Konrad von Würzburg, Der Trojanische Krieg, V. 24130-24139.

55 Vgl. z. B. Konrad von Würzburg, Der Trojaniscbe Krieg, V. 31170-31175.

56 Vgl. z. B. Jauß, »Allegorese, Remythisierung und neuer Mythus«, S. 189: Der »postallegorische Mythos des Hochmittelalters« entwickle sich aus einem "Erzählrest» des Mythos, der sich semantischen Fixierungen durch allegoretische Auslegung grundsätzlich entzogen habe. Eine grundsätzliche Resistenz eines »unüberwundenen Restes « von Mythen in Prozessen wissenschaftlicher Rationalisierung ist Thema auch der fünften Diskussion des iTerror und Spiek-Kolloquiums, vgl. »Mittelalter und Renaissance«. Vgl. auch Max Wehrli, "Antike Mythologie im christlichen Mittelalter", in: Deutsche Vierteljabrsscbrift für Literaturvissenschaft und Geistesgeschichte 57/1983, S.18-32, insbes. S.24f. sowie Manfred Kern, »Einführung in Gegenstand und Konzeption", in: Alfred Ebenbauer/Manfred Kern/ Silvia Krämer-Seifert (Hrsg.), Lexikon der antiken Gestalten in den deutschen Texten des Mittelalters, Berlin, New York 2003, S. IX-XCI, der vom "Unerledigte[n] und Unerledigbare[n] des Mythos (S. XIX) in mittelalterlichen Deutungssystemen spricht. Im Hintergrund dieser $>$ Restbestandsthese von mythischer Selbstreferenz ist die Forschungsoptik der Warburg-Schule zu sehen, die mittelalterliche Antikenrezeption vornehmlich vom Fluchtpunkt der Renaissance aus in den Blick nahm; vgl. etwa zum »Auflösungs- oder Dekompositionsprozeß« von Mythen im Mittelalter Seznec, Das Fortleben der antiken Götter, S. 157; Panofsky, Die Renaissancen der europäischen Kunst, S. 103 (»Zerlegung«). 
renz und Fremdreferenz wären hier genauer zu sichten. Gleichwohl bestätigen sowohl literarische Inszenierung als auch theoretische Reflexionen die Existenz eines gemeinsamen Feldes, auf dem Mythos im 12. und 13. Jahrhundert als prekäre Redeform entfaltet wird, die ganz ausdrücklich auf Fremdreferenz setzt, während zugleich irritierende Selbstreferenzen mitgeführt werden. Mythen werden so zwar als Repräsentationsformen konzipiert und inszeniert, d.h. als Erzählungen, die mittels fremdreferentieller Umstellungspraktiken in Wissensordnungen eingebunden werden können, doch treten mythologische Figuren zugleich selbstreferentiell als wissbare Größen oder narrative Handlungsträger in Erscheinung. ${ }^{57}$ Führt die Unterscheidung von Präsenz und Repräsentation auf die mittelalterliche Zeichentheorie der Mythenreferenz, so wird mit ihr ein sowohl theoretisch als auch literarisch artikuliertes Feld von Äußerungen greifbar, das den Zeichenstatus von Mythen (als Verhüllung oder significatio für andere Sinnmöglichkeiten) produziert und unterläuft. Zwischen den Extremen, bloß auf Wissensordnungen beziehbar oder aber selbst wissbar zu sein, beginnen Mythen und mythologische Figuren zu changieren. Die Umrisse dieses Feldes gilt es nun genauer abzustecken.

\section{Gibt es einen Mythosdiskurs des Mittelalters?}

Lässt sich angesichts der skizzierten Redeform der fremdreferentiellen Umstellung von einem kohärenten Mythosdiskurs des Mittelalters sprechen oder sind die betrachteten Phänomene anderen Diskursen wie der Naturphilosophie, der Grammatik und Rhetorik oder aber literarischen Gattungen wie dem Antikenroman im engeren Sinne zuzurechnen? Versteht man mit Michel Foucaults Archäologie des Wissens einen Diskurs als Bündel von Formationsregeln, die durch spezifische Regularitäten (1.) Modalitäten, (2.) Begriffe, (3.) Gegenstände und (4.) Strategien von Äußerungen aufeinander be-

57 Besonders deutlich wird diese Spannung in zeitgenössischen Mythographien, die dieselben Gegenstände zu konträren Zeichenformen ausarbeiten: Während etwa die Integumenta Ovidii des Johannes von Garland (ca. 1180-1272) Ovids Metamorphosen als integumenta inszenieren, deren verborgene Wahrheiten es freizulegen gelte, verzichtet der Fabularius Konrads von Mure (um 1210-1281) gänzlich auf integumentale Deutung und bietet seine fabulae, allen voran diejenigen Ovids, ausschließlich narrativ dar. Vgl. zu Johannes von Garland zusammenfassend Chance, Medieval Mythography, Bd. 2, S.236-252; zu Konrad von Mure die Einleitung zu Conradi de Mvre Fabularivs, Tom van de Loo (Hrsg.), Turnhout 2006, insbes. S. XLIV-LI. 
ziehen, so lässt sich durchaus das Profil eines mittelalterlichen Mythosdiskurses rekonstruieren. ${ }^{58}$

(1.) Modalitäten. Wie herauszuarbeiten war, wird das Sprechen über Mythos im Mittelalter von Verkettungslogiken organisiert, die Narrative nicht nur zu Erzählkernen dekomponieren, ${ }^{59}$ sondern diese zugleich mit anderen Aussagen verknüpfen, die als eigentliche Bezeichnung deklariert werden. Was Ideen- und Begriffsgeschichte traditionell als Euhemerismus, Mythenallegorese oder integumentale Hermeneutik beschreiben, fügt sich zu einem Bündel von Andersreden, die zwischen Selbstreferenz und Fremdreferenz unablässig pendeln. Dass Selbstreferenz in der Regel als irrtümlich, irreführend oder bloß fiktiv disqualifiziert wird, sollte nicht den Blick dafür verstellen, dass auch diese Selbstreferenz produziert und reproduziert wird. Nicht bloße Fremdreferenz, wohl aber fremdreferentielle Umstellungsvorgänge kennzeichnen demnach diesen Redemodus des Sinnwechsels auf vielfältigen Ebenen mythographischer Texte.

(2.) Begriffe. Zur Bezeichnung dieser Praxis werden spezifische Begriffe antiker Mythosdiskurse übernommen, aber auch weitere Lehnbegriffe geprägt. Geläufig sind zum einen Substantive wie $\mu$ ṽ os (mythos), $\mu v \vartheta o \lambda o \gamma i \alpha$

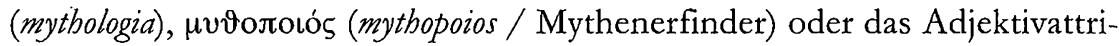

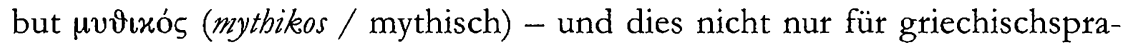
chige Autoren der Spätantike und des byzantinischen Mittelalters. ${ }^{60}$ Auch als

Vgl. Michel Foucault, Archäologie des Wissens, Frankfurt a. M. 1981, S. 48-103. Mit diesen Kategorien greife ich nur Teilaspekte des foucaultschen Diskurskonzeptes auf - jene Begriffe, die mir für den hier verfolgten philologischen Zugang analytisch besonders aufschlussreich scheinen. Mit dieser Auswahl folge ich Michael Titzmann, »Kulturelles Wissen - Diskurs - Denksystem. Zu einigen Grundbegriffen der Literaturgeschichtsschreibung", in: Zeitscbrift für französische Sprache und Literatur 99/1989, S. 47-61, insbes. S. 51-53.

59 Gerade die Zerlegung antiker Mythologien im Mittelalter hat die Forschung seit je beschäftigt: Schon Seznec untersucht die »Dekomposition« von Mythen (Seznec, Das Fortleben der antiken Götter, S. 157), Richard Newald spricht von "A tomisierung" (Richard Newald, Nacbleben des antiken Geistes im Abendland bis zum Beginn des Humanismus. Eine Überschau, Tübingen 1960, S. 192f. und S.217, hier vor allem im Hinblick auf die philosophische Rezeption).

60 Vgl. Justinus Martyr, »Apologia pro christianis«, in: Patrologiae cursus completus. Series Graeca [im Folgenden: PG]. Jacques Paul Migne (Hrsg.), Bd. 6, Paris 1857, Sp. 363B $(1,23)$ und $369 \mathrm{~A}(1,26)$. - Clemens von Alexandria, "Cohortatio ad gentes", in: $P G 8$, Sp. 73A-B (2) und 238B (12); "Stromata«, in: PG9, Sp. 89B-92A $(5,9)$ und 244B (6, 3). - Origenes, Contra Celsum libri VIII. Miroslav Marcovich (Hrsg.), Leiden u. a. 2001, S. $81,6(2,5)$; S. 252, 27 und S. 253, $5(4,28)$; S. 255, 6, S. 256, 14f., S. 256, 19 f. und S. 257, 3 (4, 39); S. 264, 26, S. 265, 12 und S. 265, 21 (4, 48); S. 268, 4 $(4,50)$. - Methodios von Olympos, "Convivium decem virginum«, in: PG 18, 
lateinische Lehnworte begegnen mythos, mythicon oder mitologia bei mittelalterlichen Mythographen - etwa in Werken, die auf 'Texte und Mythoskonzepte Varros, Martians oder Fulgentius' zurückgreifen. ${ }^{61}$ Die althochdeutsche Übersetzung von Martians mythographischer Enzyklopädie De nuptiis Pbilologiae et Mercurii durch Notker Labeo zeigt zudem mit einem experimentalen Übersetzungsversuch für mithos, dass auch in frühen volkssprachlichen Übertragungen eine bislang übersehene mittelalterliche >Arbeit am Mythosbegriffı nachweisbar ist - eine Begriffsarbeit, die differenziertes Bemühen

Sp. 161C-165B (14). - Alexander von Lykopolis, "Tractatus de placitis manichaeorum", in: PG 18, Sp. 425A-B (10) und 445B-C (25). - Synesios, "De providentia«, in: $P G$ 66, Sp. 1213B (1,2). - Photios, "Bibliotheca«, in: $P G$ 103, Sp. 604C-605D (189).

61 Vgl. z. B. die Wortbelege von ımythos in Martians De nuptiis Philologiae et Mercurii. James Willis (Hrsg.), Leipzig 1983, S. 29, 6 (2, 100), S. 57, 24 (2, 220) und S. 59, 1 $(3,222)$. Den deutlichsten Übergang von griechischer und lateinischer Terminologie stellt Augustinus in Auseinandersetzung mit Varros Antiquitatum rerum bumanarum et divinarum libri $X L I$ her: "Deinde illud quale est, quod tria genera theologiae dicit esse, id est rationis quae de diis explicatur, eorumque unum mythicon appellari, alterum physicon, tertium civile? Latine si usus admitteret, genus quod primum posuit, fabulare appellaremus; sed fabulosum dicamus; a fabulis enim mythicon dictum est, quoniam $\mu$ ṽ seine Aussage, es gebe drei Arten der Theologie, das heißt der Darstellung bezüglich der Götter, von denen eine die smythische Theologier genannt wird, eine andere die snaturphilosophische Theologier und die dritte die staatstheologies? Wenn es der lateinische Sprachgebrauch erlaubte, sollten wir die erstgenannte Art die >fabelartige ( genus fabulare] nennen. Aber lasst sie uns `fabulös` [fabulosum] nennen; der Ausdruck smythisch [ [mytbicon] ist nämlich von Fabel abgeleitet, da die Fa-

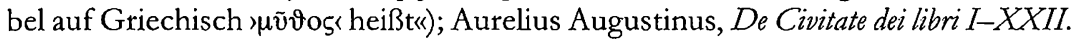
Bernhard Dombart/Alfons Kalb (Hrsg.), Bd. 1, Turnhout 1955, S.170f. (6, 5, 1-6). Vor Augustinus ist mythiconc u. a. bei Tertullian, Ad nationes libri duo. Jan W. P. Borleffs (Hrsg.), Leiden u. a. 1929, S. 37, 13 und S.37, 15 (2, 1), S.40, $16(2,3)$ und S. 49, $3(2,7)$ belegt. Auch Johannes Ridewall (gest. nach 1340) verwendet die entlehnten Ausdrücke smithologia und mithoss: vgl. Liebeschütz, Fulgentius metaforalis, S. 70 (Kap. "Ydolatria«). Für weitere Belege vgl. Horstmann, »Mythosbegriff“, S. 7-10. - Das Corpus der `Library of Latin Texts (Series A)< weist für die Texte der Patristik und der erfassten mittelalterlichen Autoren (im Zeitraum von 736-1500) insgesamt 43 Belege für mythos, mytbicon/mytbicus, mitologia und Ableitungen (mythopoeia; mythistoria; einschl. griechischer Schreibungen im lateinischen Text) aus (Onlinerecherche unter www.brepolis.net durchgeführt am 21.02. 2011). Dieser Befund wäre in seinem Aussagewert in historisch-semantischer Perspektive näher zu untersuchen, doch zeigt schon die relativ geringe Belegzahl, dass sich der mittelalterliche Mythosdiskurs nicht terminologisch auf den Begriff mythos konzentriert. Übergänge zu anderen Ausdrücken (z. B. integumentım), Neuprägungen und subterminologische Begriffsverwendungen bestimmen vielmehr den mittelalterlichen Diskurs. 
um spezifische Bezeichnungsmöglichkeiten für mehrdeutige Redeweise belegt. ${ }^{62}$ Auch im Mittelalter kursieren also spezifische Bezeichnungen für $\mathrm{My}$ thos, von denen integumentum oder involucrum (Verdeckung, Verhüllung) nur die bekanntesten sind. Dies betrifft nicht zuletzt das Wortfeld zu lat. fabula, das als Standardausdruck des Mythosbegriffs im Mittelalter gilt. ${ }^{63}$ Bei genauerem Hinblick zeigen sich auch hier schon frühe Differenzierungsinteressen: Der Ausdruck fabula allein kann den doppelbödigen Irrtum heidnischer Götterkulte und ihrer Glaubenserzählungen nicht erfassen - Isidor von Sevilla akzentuiert sie daher attributiv als »vanae fabulae«. ${ }^{64}$ Auch der im gesamten Mittelalter rezipierte Macrobius-Kommentar zum Somnium Scipionis unterscheidet programmatisch zwischen Fabeln wie denjenigen Äsops, die vollständig aus erdichteten Lügen bestünden, und einer unzutreffenden Äußerungsweise, die hingegen Wahrheit in erdichteter Gestalt vortrage - für diese Erzählform der Mythen prägt Macrobius den Ausdruck narratio fabulosa, der auch in Mythographien des hohen Mittelalters begegnet. ${ }^{65}$

62 Nach dem Zeugnis der Handschrift St. Gallen, Stiftsbibliothek, CSg 872 (11. Jahrhundert) übersetzt Notker die martiansche Pluralform »mithos poetice« mit ahd. »diu mêterlichen spél« (’dichterische Sagen, gleichnishafte Erzählungen'); Notker der Deutsche von St. Gallen, Die Hochzeit der Pbilologie und des Merkur. Diplomatischer Textabdruck, Konkordanzen und Wortlisten nach dem Codex Sangallensis 872. Evelyn Scherabon Firchow unter Mitarbeit von Richard Hotchkiss und Rick Treece (Hrsg.), Bd. 1, Hildesheim u. a. 1999, S. 89 (Nc08910 und Nc08914). Notker wählt mit ahd. spel einen Ausdruck, der nicht einfachhin `Erzählung، meint, sondern schon jene Doppelung von Selbstreferenz und Fremdreferenz konnotiert, die für mehrdeutiges figuratives Sprechen kennzeichnend ist. Vgl. Elmar Seebold (Hrsg.), Chronologisches Wörterbuch des deutschen Wortschatzes. Bd. 2. Der Wortschatz des 9. Jabrbunderts. Berlin, New York 2008, S. 785f., s.v. sspek.

63 Vgl. Werner Betz, "Zur Wortgeschichte von >Mythos«, in: Hugo Moser/Heinz Rupp/Hugo Steger (Hrsg.), Deutsche Sprache. Geschichte und Gegenwart. Festschrift für Friedrich Maurer zum 80. Geburtstag, Bern, München 1978, S.21-33, insbes. S. 22.

$64 \mathrm{Vgl}$. Isidor, Etymologiae (8,11). »Vanae fabulae« ist äquivalenter Ausdruck zu $\mu$ ṽ xєvoi (lleere Erzählungens) - eine Kampfformel, die in der Debatte zwischen Celsus und Origenes gefallen war; vgl. Origenes, Contra Celsum, S. 22, $12(1,20)$.

${ }^{65}$ Macrobius, In somnium Scipionis, S. 5, 11-13 (1, 2, 7): "Fabulae, quarum nomen indicat falsi professionem, aut tantum conciliandae auribus voluptatis, aut adhortationis quoque in bonam frugem gratia repertae sunt" - grundsätzlich treffen fabulae »falsche Aussagen, was entweder um des Vergnügens willen oder zur Unterweisung" geschehe. Zur Unterscheidung von äsopischer Fabel und narratio fabulosa vgl. ebd., S. 5, 22-27 (1, 2, 9); dazu Stock, Myth and Science, S. 44f. Im 12. Jahrhundert begegnet der Ausdruck snarratio fabulosar z. B. in der oben zitierten integumentum-Definition des (pseudo-)bernardinischen Aeneis-Kommentars wie auch in Bernardus' Macrobius-Kommentar; zur Kontinuität von Macrobius' fabula-Unterscheidung vgl. die Einführung zu: »Poetic Fiction and Truth: William of 
Mythos als Erzählform zwischen Wahrheit und Lüge setzt damit in etablierten Begriffsfeldern der doppelten Rede (fabula, involucrum, integumentum) eine Unruhe neuer Attributionen, Differenzierungen und Substitutionen frei, in denen sich die referentielle Unruhe dieser Erzählform selbst spiegelt. Diese Begriffsgeschichte wäre eingehend erst noch zu erforschen; für die hier verfolgte Leitfrage ist jedoch schon die allgemeine Beobachtung aufschlussreich, dass Mythen und Mythenauslegung weder in einem undifferenzierten fabula-Diskurs aufgehen (so das Argument der Kontinuitätsthese), noch dem Feld geistlicher Allegorese zugeschlagen werden (so die Okkupationsthese), sondern mittelalterliche Autoren für die Objekte mythographischer Praxis vielmehr spezifische Bezeichnungen prägen.

(3.) Gegenstände. Im Schnittfeld von mythographischen Redeverfahren und Bezeichnungen tritt ein Gegenstandsspektrum in den Blick, das sich durchaus nicht in Götter- und Heroenerzählungen erschöpft. Als integumenta gelten auch zu Göttern erhobene Prinzipien oder Menschen der Antike, die wie der Arzt Aeskulap oder die Magierin Medea aufgrund herausragender Fähigkeiten verehrt wurden - darin schließen mittelalterliche Mythographien an antike Diskurse an. Darüber hinaus werden im gesamten Mittelalter unterstützt nicht zuletzt vom Begriffsgebrauch des Neuen Testaments ${ }^{66}$ mythosspezifische Redepraktiken verwendet, um konkurrierende Glaubenslehren und -kulte als dämonistische Irrtümer zu diffamieren. Als ein solcher theologischer "Kampfbegriff« ist der Mythosbegriff nicht nur im frühen Christentum oder in der Patristik belegt, sondern durchzieht auch lateinische und volkssprachliche Texte des hohen Mittelalters: ${ }^{67}$ Für Augustinus wie für Herbort von Fritzlar sind Dämonen und Teufel Urheber bzw. Subjekte von Mythen. ${ }^{68}$

Ein wachsendes Interesse an platonischer Kosmologie und aristotelischer Naturphilosophie zieht ab dem 12. Jahrhundert neue Gegenstände auf das

Conches, \Bernard Silvester, Arnulf of Orléans, and Ralph of Longchamps«, in: Alastair J. Minnis/Alexander B. Scott (Hrsg.), Medieval Literary Theory and Criticism. c. 1100 - c. 1375. The Commentary-tradition. Überarb. Aufl., Oxford 1991, S.113-126, insbes. S.118f. Bis in Mythosdiskussionen der Neuzeit (etwa in Francis Bacons Mythoskonzept des verhüllten Wissens) lässt sich dieses Differenzierungsbemühen um den Fabelbegriff nachverfolgen.

${ }^{66}$ Vgl. 1 Tim 4,7; 2 Tim 4,4; Tit 1,14;2 Petr 1,16.

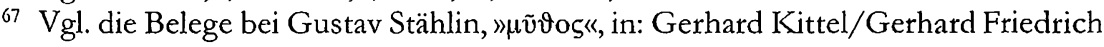
(Hrsg.), Theologisches Wörterbuch zum Neuen Testament, Bd. 4, Stuttgart 1966, S. 769-803.

68 Vgl. Augustinus, De civitate dei, S. 170-178 (6,5-6,8); Herbort von Fritzlar, Liet von

Troye, V. 3497-3510. 
Feld der Mythographie: ${ }^{69}$ Prozesse der Veränderung in der Natur und Sternkonstellationen, kosmologische Deutungsmodelle wie die Erzählung vom Welt-Ei, aber auch Parallelentwürfe zur christlichen Raumordnung wie Unterwelttopographien gehören zu den Gegenständen, die Mythographien repräsentieren und diskutieren. Welche Komplexität die Objektbereiche mittelalterlicher Mythographie gewinnen, belegt Ende des 12. Jahrhunderts Alberichs De diis gentium: Kulte und Götternamen der griechischen, römischen und ägyptischen Polytheismen werden nicht mehr attackiert, sondern in einen gemeinsamen fremdreferentiellen Diskurs über Kosmologie, Ethik, Physik und interkulturelle Sprach- und Zeichentheorie eingebunden.

Die Grenzen öffnen sich weiter und werden damit zunehmend unscharf. Gehörte es bis zu Beginn des 12. Jahrhunderts zu den Kriterien mythischer Objekte, einem der vorchristlichen Polytheismen zu entstammen bzw. darauf zu referieren, so wird selbst eine so basale Leitunterscheidung unsicher, wenn Wilhelm von Conches die Aussage des Genesis-Berichts als Mythos charakterisiert, dass sich oberhalb des Firmaments Wasser befinden könne. ${ }^{70}$ Gottes Schöpfung der Welt als mittelalterlicher Mythos? Kaum lässt sich angesichts solcher Veränderung des Gegenstandsbereichs mittelalterlicher Mythoskonzepte jedenfalls von einem diskursgeschichtlich stabilen Spektrum sprechen. Der um 1273 vollendete Fabularius Konrads von Mure umrahmt seinen mythographischen Hauptteil, bestehend aus einer Genealogie der Götter und ihrer Beschreibungen, mit einem historischen Abriss vom Urgroßvater Abrahams bis zur Geburt Christi sowie einer alphabetischen Liste von Edelsteinen, Bäumen und Kräutern. ${ }^{71} \mathrm{Im}$ Unterschied zu seinen distinkten Redemodalitäten und Bezeichnungen zeigt sich das Feld mittelalterlicher Mythographie in der Perspektive seiner Gegenstände also nicht als trennscharfer Diskurs, sondern allenfalls als diskursähnliche Formation.

(4.) Strategien. So komplex sich die Evolution dieser Formation vollzieht, sie lässt doch mindestens drei Strategien erkennen, die ihre Geschichte beharrlich durchziehen. Auf Ebene der Institutionalisierung lassen sich zum

69 Vgl. Chance, Medieval Mythography, Bd 2; Stock, Myth and Science; Dronke, Fabula, insbes. S. 79-153.

70 Zweifel am Literalsinn der Genesis haben freilich Vorläufer in der christlichen Exegese - schon Origenes etwa verwirft die Schöpfung Adams und die Verwandlung von Lots Frau als unglaubwürdig; vgl. dazu Westra, »Allegorical interpretation«, S. 283.

71 Vgl. Konrad von Mure, Fabularius; dass selbst der Hauptteil die Grenzen zwischen Mythologie und Geschichte unscharf werden lässt, belegen darin etwa die Einträge zu Julius Caesar, Pompeius, Cato oder Pontius Pilatus, die in die mythographische Reihe von Abas bis zu Zoroaster eingeordnet werden. 
einen Autorisierungsstrategien greifen: Mythographen von Hilarius von Poitiers über Alanus von Lille und Heinrich von Veldeke bis zu Konrad von Würzburg betonen die Uneigentlichkeit mythologischer Verhüllung als Geltungssteigerung eines Wissens, das sich demonstrativ vor profanem Zugriff schützt. Der prekäre Referenzstatus von Mythen erscheint in dieser Perspektive nicht als Mangel, sondern umgekehrt als Wissensausweis von gehobener Dignität. Wenn die volkssprachigen Erzählliteraturen im 12. Jahrhundert vor allem mit Antikenromanen einsetzen, so kann der Geltungsanspruch höfischer Erzählkultur auf diese Diskursstrategie der epistemischen Geltungssteigerung aufbauen.

Zweitens kennzeichnet mittelalterliche Mythographie die grundlegende Strategie, epistemische Energie zu erzeugen. Mit ihren unablässigen referentiellen Umstellungsakten zielt sie primär auf Aktualisierung und Aktivierung von Wissen - epistemische Vergegenwärtigung von mythographischem Wissen bildet damit einen Spezialfall mittelalterlicher >Erneuerungskulturı, die sich allgemein in der Spannung von Fremdbezug und Selbstbezug entfaltet. ${ }^{72}$

Drittens verfolgen Mythographien von der Patristik bis zum Spätmittelalter Experimente mit erhöhter Irritabilität für Fremdheit. Sie entfalten Mythos als Redepraxis, die alteritäre Zeichensysteme, Praktiken und Wissensformen nicht restlos in christliche Währung ummünzt, sondern sich mit der Andersheit des Anderen fortwährend reizt - in Semantiken des Irrtums, des Uneigentlichen, des Fiktiven. Man könnte damit mittelalterliche Mythographie als einen Diskurs im Zustand permanenter >Autoimmunreaktion betrachten. Ihre Reizbarkeit und dadurch bedingte Tendenz zur Hyperkommunikation wären Phänomene, bei denen das Forschungsparadigma der Alterität konkret ansetzen könnte, ohne globale Annahmen (etwa zur Fremdheit mittelalterlicher Rationalität) voraussetzen zu müssen.

Damit lässt sich die Ausgangsfrage klar beantworten: Es gibt durchaus einen Mythosdiskurs des Mittelalters, für den wir die Vokabel Mythos ge-

72 Diese mythographische Energie wird vielfach als 'Erneuerung beschrieben, mit der Erzählungen lebendig blieben oder wieder würden - so etwa in Baudris von Bourgueil Relektüre der fulgentianischen Mitologiae: „Credo, vivit adhuc nobiscum fabula lecta, / Vivit enim quicquid fabula significat (»Ich glaube, die vorgetragene Erzählung lebt bis jetzt unter uns, / denn was die Erzählung auch immer bezeichnet, lebt«); Baudri von Bourgueil, Carmina. Karlheinz Hilbert (Hrsg.), Heidelberg 1979, S. 222 (154, 653f.). Zur Dimension des Erneuerns vgl. grundsätzlich Burkhard Hasebrink: »Die Ambivalenz des Erneuerns. Zur Aktualisierung des Tradierten im mittelalterlichen Erzählen«, in: Ursula Peters/Rainer Warning (Hrsg.), Fiktion und Fiktionalität in den Literaturen des Mittelalters. Jan-Dirk Müller zum 65. Geburtstag, München 2009, S. 205-218 sowie Björn Reichs Beitrag in diesem Band. 
brauchen können, ja sogar benötigen. Während allerdings Redemodalitäten und Begriffe dieses Diskurses ein deutliches Profil bilden, zeigen sich Gegenstände und Strategien weniger stabil bzw. deutlich irritabel. Es könnte sich daher empfehlen, eher von einer diskursähnlichen Formation statt von einem voll konstituierten Diskurs zu sprechen.

Welchen Befund liefert dies für das Verhältnis von Mythosdiskursen und Konzeptionen des Literarischen? Das Ergebnis der Analyse lässt sich in zwei Beobachtungen resümieren. Mit seinem ausgeprägt repräsentationalen Charakter, der sich in fremdreferentiellen Umstellungsakten manifestiert, weist der Mythosdiskurs des Mittelalters zum einen relativ dünne Grenzen zu einer Vielzahl anderer Wissensordnungen auf. Zum anderen umkreist dieser Diskurs die Herausforderung, die Selbstreferenz von Mythen nicht überspringen oder beseitigen zu können, sondern diese reproduzieren zu müssen - und damit auch die Präsenz von Narrativität und Bildlichkeit zuzulassen, wenn nicht sogar zu verstärken. Wie ich abschließend skizzieren möchte, könnte der Mythosdiskurs damit Voraussetzungen für Entwicklungen der literarischen Kommunikation schaffen, die Walter Haug als epochales Ereignis des 12. Jahrhunderts beschrieben hatte: die Fiktionalisierung des volkssprachlichen Erzählens. ${ }^{73}$

IV. Mythos und das Unbehagen literarischer Repräsentation: Zur Interferenz von Mythosdiskurs und fiktionalem Erzählen um 1200

Mythostheorie und Literaturtheorie teilen nicht nur im Bereich der lateinischen Poetologie des Mittelalters eine lange Interferenzgeschichte. ${ }^{74}$ Seit den 1970 er Jahren hat die mediävistische Forschung die Spuren integumentaler Poetologie auch in volkssprachlicher Epik verfolgt und diskutiert. ${ }^{75}$ Kontro-

73 Vgl. Walter Haug, Literaturtheorie im deutschen Mittelalter. Von den Anfängen bis zum Einde des 13. Jabrbunderts. 2. Aufl., Darmstadt 1992; vgl. zuletzt auch Walter Haug, "Literaturtheorie und Fiktionalitätsbewußtsein bei Chrétien de Troyes, Thomas von England und Gottfried von Straßburg«, in: Peters/Warning (Hrsg.), Fiktion und Fiktionalität, S. 219-234.

74 Vgl. Winthrop Wetherbee, Platonism and Poetry in the Tivelfth Century. The Literary Influence of the School of Chartres, Princeton 1972; für einen Überblick vgl. auch Winthrop Wetherbee, "The Study of Classical Authors. From Late Antiquity fo the Twelfth Century«, in Alastair Minnis/Ian Johnson (Hrsg.), The Cambridge History of Literary Criticism. Bd. 2. The Middle Ages, Cambridge 2009, S. 99-144.

75 Für Verbindungen von lateinischer integumentum-Lehre und volkssprachlicher Literarästhetik plädierte früh Hennig Brinkmann, »Verhüllung (IIntegumentum`) als literarische Darstellungsform im Mittelalter«, in: Albert Zimmermann (Hrsg.), 
vers haben etwa Fritz Peter Knapp und Christoph Huber erörtert, inwiefern die mittelhochdeutsche Literaturdidaktik Thomasins von Zerklære das integumentum-Konzept übernehme und damit ein adäquates Beschreibungsmodell für den zeitgenössischen Aventiureroman liefere. ${ }^{76}$

Die Debatte befindet sich trotz jüngerer Ergänzungen seitdem in der Aporie: ${ }^{77}$ Weder bieten Thomasin oder der höfische Roman um 1200 explizite Reflexionen zur Mythosförmigkeit, die über einige viel diskutierte An-

Der Begriff der repraesentatio im Mittelalter. Stellvertretung - Symbol - Zeichen - Bild, Berlin, New York 1971, S. 314-338; vgl. auch Brinkmann, Mittelalterliche Hermeneutik, S.169-198. Ausführlich hat ihm Knapp, »Historische Wahrheit und poetische Lüge«, insbes. S. 623f. auf begriffsgeschichtlicher Materialbasis zu shistoriar und ,fabular widersprochen; vgl. zuletzt auch Fritz Peter Knapp, "Fabulae - parabolae historiae. Die mittelalterliche Gattungstheorie und die Kleinepik von Jean Bodel bis Boccacciou, in: Mittellateinisches Jabrbuch 44/2009, S.97-117. Skeptisch auch Walter Haug, "Fiktionalität zwischen Lüge und Wahrheit: Thomasin von Zerklære und die Integumentum-Lehre«, in: Ders., Literaturtheorie, S. 228-240, insbes. S. 231: »die Integumentum-Lehre war für eine Poetik des Chrétienschen Modells untauglich«.

76 Christoph Huber, »Höfischer Roman als Integumentum? Das Votum Thomasins von Zerklaere«, in: Zeitschrift für deutsches Altertum 115/1986, S. 79-100 rekonstruiert die Romankonzeption Thomasins als grundsätzlich integumental, verweist jedoch auf Grenzen einer schematischen Übertragung des integumentum auf den Artusroman; Fritz Peter Knapp, »Integumentum und Âventiure: nochmals zur Literaturtheorie bei Bernardus (Silvestris?) und Thomasin von Zerklære«, in: Literatumvissenschaftliches Jabrbuch N. F. 28/1987, S. 299-307 weist gegen Huber sowohl ein integumentales Verständnis Thomasins als auch Zusammenhänge zur Romanpoetik zurück: Integumentale Differenzierungstypen der fabula seien nicht mit der Exemplarik von Aventiuren zu verrechnen. Vgl. dazu die Duplik von Christoph Huber, "Zur mittelalterlichen Roman-Hermeneutik: Noch einmal Thomasin von Zerklære und das Integumentum", in: Volker Honemann (Hrsg.), German Narrative Literature of the Tivelfth and Thirteenth Century. Studies Presented to Roy Wisbey on bis Sixty-Fifth Birthday, Tübingen 1994, S. 27-38. Die Dissertation von Rolf-Peter Lacher, Die integumentale Methode in mittelhochdeutscher Epik, Frankfurt a. M. u. a. 1988 bleibt sachlich wie methodisch hinter dieser Debatte zurück; deren Stand findet sich zusammengefasst bei Christoph Huber, »Integumentum«, in: Georg Braungart u. a. (Hrsg.), Reallexikon der deutschen Literaturvissenschaft, Bd. 2, Berlin, New York 2000, S. 156-160.

77 Der Überblick zur Poetologie der Lüge, mit dem z. B. Ulrich Ernst, »Lüge, integumentum und Fiktion in der antiken und mittelalterlichen Dichtungstheorie. Umrisse einer Poetik des Mendakischen«, in: Das Mittelalter 9/2004, S. 73-100 für eine diachrone Fiktionalitätstheorie plädiert, könnte Neuanstöße in der integumentumDebatte bieten (so z. B. zur volkssprachlichen Lügenpoetik des 12. und 13. Jahrhunderts: S. 93-98). Ernsts Darstellung verdeutlicht, dass das literarische Fiktionalitätsproblem in einem weiteren Kontext referenzunsicherer Rede im Mittelalter zu verorten ist. 
klänge hinausgingen, noch stellen die Romane Chrétiens de Troyes oder Hartmanns von Aue ausschließlich auf Vermittlung fremdreferentieller Wahrheit $a b$ - sei es im Bezug auf religiöse, ethische oder soziale Normen. ${ }^{78}$ Aus der Perspektive des mittelalterlichen Mythosdiskurses könnten sich alternative Möglichkeiten bieten, diese Aporie aufzulösen und den Fiktionalisierungsschub des Romans um 1200 zu beschreiben.

Wie Rainer Warning unterstrichen hat, begründet nicht die bloße Auskoppelung von Narration aus exempelförmigen Deutungsrahmen schon die Fiktionalität des Artusromans. ${ }^{79}$ Entscheidend hierfür sind vielmehr Akte des Fingierens, die zugleich imaginär und regelgebunden orientiert sind, indem sie einerseits auf sich selbst referieren (z. B. in der Selbstbezüglichkeit von Erzählstrukturen, Regeln der fiktionalen Welt oder der Dysfunktionalität des Fingierens), andererseits auf diskursive Strukturen jenseits ihres fiktiven Entwurfs Bezug nehmen. Mit anderen Worten: Auch das fiktionale Romanerzählen verdankt sich Spannungsbeziehungen von Selbstreferenz und Fremdreferenz, die Warning grundlegend als »Transgression « fasst. ${ }^{80}$

Diese Spannung verdankt sich nicht erst dem Experiment einer $>$ Neuerfindung von Fiktionalität - sie findet sich vorgebildet in Mythosdiskursen. Wie ich zu skizzieren versuchte, kreisen mittelalterliche Mythographien weniger um einfache Oppositionen von Wahrheit und Lüge als vielmehr um Akte der Referenzumstellung, die prekäre Dynamiken von Selbstreferenz und Fremdreferenz freisetzen. Mythen erzeugen ein produktives Unbehagen bei ihren mittelalterlichen Bearbeitern, ${ }^{81}$ weil ihr Sinn nicht transparent ist für wahrheitsfähige Bedeutung, sondern erst erzählt, bearbeitet und um-

78 Vgl. Haug, »Literaturtheorie und Fiktionalitätsbewußtsein«.

79 Rainer Warning, „Fiktion und Transgression«, in: Peters/Warning (Hrsg.), Fiktion und Fiktionalität, S. 31-55.

80 Vgl. Warning, »Fiktion und Transgression«, S. 42: »Transgressiv ist somit der Akt des Fingierens selbst."

81 Sigmund Freud charakterisiert mit dem Begriff des Unbehagens den Effekt eines Widerstreits zwischen Gemeinschaftsbedürfnis und dem individualen Bedürfnis nach Triebabfuhr; ihr Kompromiss vollziehe sich auf Ebene der Kultur, die sozialverträgliches Triebleben ermögliche, zugleich aber Triebbegrenzung verlange und somit bei ihren Subjekten Schuldgefühle produziere. Vgl. Sigmund Freud, "Das Unbehagen in der Kultur«, in: Studienausgabe. Bd. 9: Fragen der Gesellschaft. Ursprünge der Religion. Alexander Mitscherlich u. a. (Hrsg.), Frankfurt a. M. 2000, S. 191-270. In abstrakterem Sinne entlehnt, könnte der Begriff des Unbehagens pointiert den Spannungscharakter von mittelalterlicher Mythographie zwischen Restriktion und Proliferation von Referenz erfassen. Die permanente Unruhe dieser spannungsvollen Arbeit schlägt sich auch in mythographischen Texten in aggressiven Semantiken nieder, wie sie Freuds Diagnose von kulturellem Unwohlsein und Unbehagen aufgreift. 
gearbeitet werden muss, und diese prekäre Differenz von Selbstreferenz und Fremdreferenz öffnet und schließt sich in Mythographien unaufhörlich.

Damit werden Berührungspunkte von mythographischer Kommunikation und literarischen Strategien greifbar, die weder auf der Ebene expliziter Literaturtheorien des Mittelalters liegen oder auf exakter Übernahme eines integumentum-Konzepts beruhen, noch auf mythologisch einschlägige Gattungen wie den Antikenroman beschränkt sind. Zugespitzt formuliert: Mythosdiskurs und fiktionaler Roman bearbeiten invers zueinander vergleichbare Spannungen von Selbstreferenz und Fremdreferenz. Während Chrétiens modellbildendes Erzählprogramm der kunstvollen Zusammenfügung des Erzählens (»bele conjointure«) der selbstreferentiellen Sinnordnung des Romans neues Eigengewicht verleiht gegenüber der fremdreferentiellen Konstruktion von exemplarischer Bedeutung, ${ }^{82}$ operieren Mythosdiskurse in der entgegengesetzten Richtung, wenn sie schwierige Selbstreferenzen auf fremdreferentielle Bedeutung umstellen. In beiden Diskursfeldern öffnet sich dabei ein prekärer Zwischenraum des Sprechens zwischen Selbstreferenz. und Fremdreferenz. Fiktionalität wäre dann kein Sonderweg des Literarischen im 12. Jahrhundert, sondern eher als Ausdifferenzierung eines bereits etablierten, wenngleich nicht institutionalisierten Referenzmusters zu betrachten - Fiktionalität wäre unter diesen Diskursbedingungen inverse Mythologie.

Handelt es sich bei solchen Analogien bzw. Inversionen um bloße Koinzidenzen - um Parallelentwicklungen, die zwar diskursgeschichtlich nebeneinander herlaufen, sich aber gegenseitig nicht nachweislich beeinflussen? Tatsächlich lassen sich Hinweise beibringen, dass Mythosdiskurse die fiktionalen Romanexperimente Ende des 12. und zu Beginn des 13. Jahrhunderts

82 Vgl. Chrétien de Troyes, Erec et Enide. Altfranzösisch/deutsch. Albert Gier (Hrsg.), Stuttgart 2000, V. 13-18: »et tret d'un conte d'avanture / une molt bele conjointure / par qu'an puet prover et savoir / que s'escïence n'abandone / tant con Dex la grace l'an done" (Übersetzung Gier, S. 5: »und er [ $=$ Chrétien de Troyes] bringt seinerseits eine Reihe von Ereignissen, wie sie erzählt werden, in einen wohlgeordneten Zusammenhang, damit man daraus zu erweisen und zu erkennen vermag, daß man nicht klug handelt, wenn man nicht sein Wissen mitteilt, solange Gott einem die Gnade dazu gibt«). Conjointure hatte Haug als Leitwort eines Erzählprogramms gedeutet, das exemplarische Bedeutungskonstruktion durch einen "experimentellen Strukturentwurf « ersetze, der auf innertextuelle Verweisung abstelle; vgl. Walter Haug, "Chrétiens de Troyes `Ereck-Prolog und das arthurische Strukturmodellk, in: Ders., Literaturtheorie, S. 91-107, hier S. 92. Dennoch verbindet Chrétiens Erzähler diese neue Selbstreferenz mit einer traditionell fremdreferentiellen Funktion, wenn er die Erzählsituation als Exempel von Wissenstransfer charakterisiert. 
beeinflussen. Kaum ein Artusroman kommt ohne verdeckte oder offene Bezüge auf Trojaerzählungen aus, die besonders häufig in ekphrastischen Beschreibungen hergestellt werden. ${ }^{83}$ Auffällig häufig greifen metafiktionale Reflexionen des Romans auf Objekte des mythographischen Diskurses zurück oder beziehen sich offen auf mythographische Prätexte. So stattet etwa Chrétiens Erzähler in Erec et Enide den Krönungsmantel Erecs nicht nur mit Figuren des kosmologischen Wissens aus, sondern beruft sich dafür ausdrücklich auf den Mythostheoretiker Macrobius; ${ }^{84}$ Enites Pferd - reflexives Kunstobjekt des Erec-Romans par excellence - trägt bei Hartmann »das lange liet von Troiâu auf seinem Sattel eingearbeitet, die Satteldecke sei zudem Jupiters würdig; 85 in Gottfrieds Tristanroman bettet der Erzähler die erste deutsche Literaturrevue der Volkssprache in ein Gebet an Apoll und die Musen ein. ${ }^{86}$ Schwerlich wird man angesichts so prominenter Reflexionsstellen von bloßer Anspielung gelehrten Wissens sprechen wollen. Nicht nur analoge Referenzverhältnisse, sondern auch explizite Dialoge mit dem Mythos-

83 Vgl. im Anschluss an die Forschungen Haiko Wandhoffs kürzlich Björn Reich, "Helena und der Gral. Trojamythos und Adelskritik im Göttweiger Trojanerkrieg", in: Mythes à la cour, mythes pour la cour (Courtly mythologies), Alain Corbellari (Hrsg.), Genf 2010, S. 179-190, hier S. 180.

${ }^{44}$ Vgl. Chrétien de Troyes, Erec et Enide, V. 6674-6681. Zu weiteren Bezügen zwischen Chrétiens Roman und der mythenaffinen sSchule von Chartresı vgl. Donald Maddox, »Nature and Narrative in Chrétien's Erec et Enide«, in: Mediaevalia 3/1977, S. 59-82 sowie Katharina Münchberg, »Eros und Erkenntnis. Chrétien de Troyes und die theologische Ästhetik der Schule von Chartres, in: Maria Moog-Grünewald (Hrsg.), Eros. Zur Ästhetisierung eines (neu)platonischen Philosophems in Neuzeit und Moderne, Heidelberg 2006, S. 17-34.

85 Vgl. Hartmann von Aue, Erec. Mit einem Abdruck der neuen Wolfenbütteler und Zwettler Erec-Fragmente. Hrsg. von Albert Leitzmann, fortgeführt von Ludwig Wolff. 7. Aufl. besorgt von Kurt Gärtner, Tübingen 2006, V. 7545-7581 und 7658-7668; Zitat V. 7546; vgl. deutlich kürzer bei Chrétien, Erec et Enide, V. 5289-5298 [u. a. ohne Jupiter-Vergleich].

86 Vgl. Gottfried von Straßburg, Tristan und Isold. Friedrich Ranke (Hrsg.), 14. Aufl., Dublin u. a. 1969, V. 4589-4907. Dass mythologische Bezugspunkte nicht nur den Musenanruf, sondern auch die Einzelporträts von Gottfrieds Dichterschau strukturieren, hat Kern, Edle Tropfen vom Helikon, S. 174-186 gezeigt. Entsprechend erwog die Forschung schon früh grundlegende Beziehungen zum Mythosdiskurs: Charles Stephen Jaeger, Medieval bumanism in Gottfried von Strassburg's Tristan and Isolde, Heidelberg 1977 führt den gesamten Tristan auf Mythoslektüren zu Platons Timaios und Vergils Aeneis nach dem integumentalen Modell der sSchule von Chartres zurück. Zu diesen Beziehungen vgl. auch Christoph Huber, Die Aufnabme und Verarbeitung des Alanus ab Insulis in mittelhochdeutschen Dicbtungen. Untersucbungen zit Thomasin von Zerklaere, Gottfried von Straßburg, Frauenlob, Heinrich von Neustadt, Heinrich von St. Gallen, Heinrich von Mügeln und Johannes von Tepl, München u. a. 1988. 
diskurs kennzeichnen somit den höfischen Roman und seine poetologische Selbstreflexion.

$\mathrm{Zu}$ den zentralen Beschreibungsschwierigkeiten, welche die Haug'sche Fiktionalitätsthese der Literaturwissenschaft vererbte, gehört die Paradoxie, dass fiktionale Erzählentwürfe um 1200 sich der exempelförmigen Bedeutungskonstruktion verweigern, aber gleichwohl ausdrücklich Exemplarik für sich reklamieren. ${ }^{87}$ Folgt man den Spuren des mittelalterlichen Mythosdiskurses, so lässt sich ein Trägermilieu für diese zweiseitigen Referenzexperimente erschließen, welche die Karriere der Fiktionalität im 12. Jahrhundert einleiten. Es könnte daher gerade das produktive Unbehagen des mittelalterlichen Mythosdiskurses zwischen Selbstreferenz und Fremdreferenz sein, das neue Einsichten in die historischen und systematischen Grundlagen fiktionaler Rede verspricht.

${ }^{87}$ Vgl. dazu Walter Haug, »Die Problematisierung der Legende: Hartmanns 'Gregorius - Prolog«, in: Ders., Literaturtbeorie, S.134-154 und ders., »Programmatische Fiktionalität: Hartmanns von Aue ১Iweinı-Prolog«, in: Ebd., S. 119-133. 